Research Article

\title{
Mechanical Properties and Failure Modes of Thick-Walled Cylinder Granites with Different Apertures under Triaxial Compression
}

\author{
Wei Chen $\mathbb{D}^{1},{ }^{1}$ Wen Wan ${ }^{D},{ }^{1}$ Shuailong Lian, ${ }^{2}$ Senlin Xie, ${ }^{3}$ Yu Zhou, ${ }^{1}$ Wenqing Peng, \\ Wenlong Kuang, ${ }^{1}$ Xianqing Wang, ${ }^{1}$ and Shasha Tong ${ }^{4}$ \\ ${ }^{1}$ School of Resource, Environment and Safety Engineering, Hunan University of Science and Technology, Xiangtan, \\ Hunan 411201, China \\ ${ }^{2}$ School of Civil Engineering, Guizhou University, Guiyang, Guizhou 550025, China \\ ${ }^{3}$ School of Energy and Mining Engineering, China University of Mining and Technology (Beijing), Beijing 100083, China \\ ${ }^{4}$ Foreign Language School, Hunan University of Science and Technology, Xiangtan, Hunan 411201, China
}

Correspondence should be addressed to Wen Wan; wanwenhunst@163.com

Received 28 June 2020; Revised 29 July 2020; Accepted 13 November 2020; Published 26 November 2020

Academic Editor: Sanjay Nimbalkar

Copyright $\odot 2020$ Wei Chen et al. This is an open access article distributed under the Creative Commons Attribution License, which permits unrestricted use, distribution, and reproduction in any medium, provided the original work is properly cited.

\begin{abstract}
Roadway excavation changes the original equilibrium stress state of the rock mass, resulting in the loading and unloading of the surrounding rock near the free surface. After the excavation, the tangential stress increases and the radial stress decreases, which mainly cause deformation and collapse of the roadway. In order to study the strength characteristics of the surrounding rock after the excavation, one effective way is to carry out triaxial compression tests on small surrounding rock samples. Therefore, this paper focuses on the triaxial compression mechanical propertiesof thick-walled cylinder granites with an electrohydraulic, servo-controlled rock mechanics testing system (MTS-815). It studies how different pore sizes and confining pressures affect the triaxial compressive strength (TCS), deformation, and failure modes of granite samples. The results are as follows: (1) Under triaxial compression, the stress-strain curves have no obvious yield stage, and the peak TCS increases with the confining pressure $\left(\sigma_{3}\right)$. When $\sigma_{3}$ is low, there is little difference in the TCS between the complete specimen and the thick-walled cylinders. When $\sigma_{3}$ reaches $30 \mathrm{MPa} 440 \mathrm{MPa}$, the TCS of samples with apertures of $15 \mathrm{~mm}$ and $20 \mathrm{~mm}$ are obviously lower. The $\sigma_{3}$ has an obvious influence on the elastic modulus of thick-walled cylinder granites. (2) Shearing and splitting are the main failure modes under triaxial compression. When $\sigma_{3}$ is low, shear failure appears. As $\sigma_{3}$ reaches $30 \mathrm{MPa} \sim 40 \mathrm{MPa}$, split failure occurs. The area of the fracture surface increases with $\sigma_{3}$. (3) As $\sigma_{3}$ grows, the influence parameter $(m)$ of the three-dimensional Hoek-Brown criterion increases. Under the same $\sigma_{3}$, the value of $m$ presents a decreasing trend from the outer wall to the inner wall, which means the bearing capacity keeps getting lower and lower. As a result, the inner wall is most likely to be damaged. The theoretical analysis results agree well with the tests.
\end{abstract}

\section{Introduction}

With a scale-up in the sustainable development of the economy and the infrastructure, underground projects, such as tunnel, mine, water conservancy, and hydropower, advance much deeper $[1,2]$. The rocks surrounding the deep excavation are vulnerable to violent rock bursts, continuous deformation, large volume collapse, and other disasters, which lead to various accidents and casualties [3-8]. Meanwhile, the deformation and damage of the surrounding rocks are closely related to their triaxial stress-strain characteristics [9-11]. Therefore, it is of great significance to study the triaxial stress-strain mechanism of the surrounding rocks on their initiation and evolution [12-14]. It can be instructive for the design and construction of underground engineering.

During the excavation of the abovementioned underground works, interference and damage may appear around the boundary of the tunnel, cavern, and borehole [15-17]. For different excavation cases, evaluating the evolution stage 
of the fractured rocks and estimating the scope of the disturbed areas are both important [18]. For instance, Martin and Chandler [19] proposed a flaw damage judging criterion for the long-term strength of the rocks. Xue et al. [20] studied the influence of rock type, porosity, and grain size on damage. Ghazvinian et al. [21] took four different types of brittle rocks as examples and analyzed how different structures can influence damage. Based on the fractured tests and theoretical analysis, Cai et al. [22] generalized the damage mechanism of jointed rock mass. They also described the fractured surface in the main stress space according to the partial stress criterion. With the acoustic emission technique, Kim et al. [23] studied the propagation and damage criteria of fractured granite. Then, they evaluated the evolution of the progressive damage and compared their analysis with the stress-strain. Damjanac and Fairhurst [24] suggested that rocks have a low threshold strength, under which they stop deformation. They also pointed out that the threshold is about $40 \%$ of the uniaxial compressive strength. By carrying out triaxial compression tests on standard cylinder specimens under three different stress paths, Zhang et al. [25] discussed how the unloading and loading influenced the strength, deformation, and acoustic emission characteristics of rocks.

The above researches are mainly based on solid cylinder specimens. However, hollow cylinders are more commonly used in excavation engineering. Since it is difficult to prepare the thin-walled hollow cylinders and the related tests usually fail [26, 27], researchers generally do experiments with thick-walled cylinders, wherein the ratio between the wall thickness and the inner wall radius is not less than 0.2 [28]. The triaxial compression tests on thick-walled cylinders are widely used in complex stress distribution scenarios to study the deformation, strength, and fractured characteristics of rocks. It is also an effective method to study the stability of underground engineering [29, 30]. Compared with solid cylinder tests, the thick-walled cylinders have the following advantages: (1) They can simulate the stress state and path around the excavation boundary of deep the foundation pit or tunnel on a small scale and (2) they can be used as an evaluation method instead of the true triaxial test.

So far, there have been many experimental studies on thick-walled cylinders. Hoskins [26] carried out a series of tests on thick-walled cylinders under multiaxial composite stresses. Their results show that the magnitude of the intermediate principal stress and the gradient of the compressive stress have a great influence on the strength of rocks. Based on the triaxial loading and the torque test on hollow cylinders, Lee et al. [31] studied the potential effect of the stress path on the mechanical behavior of sandstone. With conventional triaxial compression tests, Yang [32] studied the deformation, strength, and damage of thick-walled cylinder sandstones under different confining pressures. Their results show that the triaxial compressive strength of sandstone decreases linearly with the increase in pore diameter. Alsayed [27] carried out tests on hollow cylinders with a pore pressure loading device, and confirmed the influence of pore pressure on strength and failure. Handin et al. [33] described the results of the compression, tension, and torsion tests with linear functions of the magnitude of the intermediate principal stress. Zhang et al. [34] conducted triaxial unloading tests with thick-walled cylinder limestone specimens. They simulated the unloading process and studied the fractured mode by unloading the internal pressure. Their results were later confirmed by Han et al. [35] based on Griffith strength theory [36, 37]. Wu et al. [38, 39] focused on thick-walled cylinder sandstones with different fillings. They did the triaxial compression test and studied the supporting performance of roadways and tunnels [38]. Wang et al. [40] carried out triaxial compression tests on thick-walled cylinder granite specimens with an electrohydraulic, servo-controlled rock mechanics testing system (MTS-815). Through the tests, they determined the strength characteristics under the coupling action of internal and external stresses. Then, they made a physical simulation on the actual rock mass around the circular pole and analyzed the test results in detail. To be specific, they studied how the radial stress gradient, the peripheral stress, and the lengthdiameter ratio can affect the compressive strength and failure modes. Finally, based on the Mohr-Coulomb [41] and Hoek-Brown criteria [42], they proposed the linear and nonlinear failure criteria of the hollow cylinder granite. Yang [43] did tests on the thick-walled cylinders made of gypsum, sandstone, and plexiglass, and studied how the confining pressure influences the deformation and failure of the roadway. Based on the thick-walled concrete cylinders made of cement mortar, Gong et al. [44] studied the influence of the unloading rate of the confining pressure on the deformation and failure of the surrounding rocks.

The abovementioned researches mainly focus on the internal and external stress difference of hollow cylinders, yet do not discuss how the confining pressure and the pore size affect the failure of the hard rock $[45,46]$. Moreover, the thick-walled cylinder suffers unequal pressures from three dimensions, in which the stress states are different at different points [47, 48]. Therefore, we carry out triaxial compression tests on the thick-walled cylinder granites with different apertures with MTS-815. The paper analyzes granite specimens on their strength, deformation, and failure characteristics under different confining pressures. Furthermore, based on the three-dimensional Hoek-Brown criterion [49], it studies the relationship between the parameter and the failure degree. This work can provide both theoretical and experimental bases of the destabilization on the rocks surrounding the deep roadway.

\section{Laboratory Tests}

2.1. Preparation of Rock Specimens. To avoid the discreteness, all the thick-walled cylinders are taken from the same intact granite. The diameter and height of the specimen are $50 \mathrm{~mm}$ and $100 \mathrm{~mm}$, respectively. The top and bottom of the specimen are polished to ensure parallelism and flatness. When processing the specimen, we control the height deviation within $\pm 0.05 \mathrm{~mm}$, and limit the unevenness deviation of the end not to exceed $\pm 0.02 \mathrm{~mm}$ [50-52]. In this experiment, all specimens are dried. Their average density is $2.765 \mathrm{~g} / \mathrm{cm}^{3}$. Then, we drill cylindrical holes of diameters $10 \mathrm{~mm}, 15 \mathrm{~mm}$, and $20 \mathrm{~mm}$ and 
number the above specimens with the prefixes $\mathrm{H}-10, \mathrm{H}-15$, and $\mathrm{H}-20$, respectively; the complete specimens are numbered with the prefix "S" (see Figure 1). Meanwhile, the detailed test parameter settings for each specimen is shown in Table 1.

2.2. Experiment Content and Test Method. The triaxial compression tests of thick-walled cylinder granites are carried out in the rock mechanics laboratory of Hunan University of Science and Technology. The instrument used in the experiment is an electrohydraulic, servo-controlled testing system (MTS-815) (see Figure 2(a)). It is the rock mechanics test equipment with the highest configuration and the best performance in Hunan University of Science and Technology.

The system consists of five main units: axial loading unit, external hydraulic loading unit, internal hydraulic loading unit, displacement-stress monitoring unit, and data acquisition control unit. The system puts axial pressure, external oil pressure, and internal water pressure on rock specimens through its coupling loading function. The maximum output load of axial stress is $2600 \mathrm{kN}$, and the maximum output confining pressure is $140 \mathrm{MPa}$. During the test, the axial and circumferential deformations are measured with the linear displacement sensors.

The test process is shown in Figures 2(b)-2(d), during which the loading methods are as follows: Firstly, we preload the axial pressure and set its value around $0.5 \mathrm{MPa}$. This step can prevent the specimen from moving before loading the confining pressure. Then, we load the confining pressure at a rate of $0.05 \mathrm{MPa} / \mathrm{s}$ until it reaches the preset value. After that, we load the axial pressure at a rate of $0.005 \mathrm{~mm} / \mathrm{s}$ until the specimen breaks.

\section{Laboratory Results and Discussion}

\subsection{Theoretical Analysis under Triaxial Compression}

3.1.1. Stress Analysis on Thick-Walled Cylinder. The stress states of thick-walled cylinder granite specimens under triaxial compression are changed by their pores. Figure 3 shows the stress distribution under confining pressure.

At each point of the specimen, the stresses can be expressed as [53, 54]

$$
\begin{aligned}
& \sigma_{r}=\frac{R^{2} p}{R^{2}-r_{0}^{2}}\left(1-\frac{r_{0}^{2}}{r^{2}}\right)=\frac{p}{1-\eta^{2}}\left(1-\frac{r_{0}^{2}}{r^{2}}\right), \\
& \sigma_{\theta}=\frac{R^{2} p}{R^{2}-r_{0}^{2}}\left(1+\frac{r_{0}^{2}}{r^{2}}\right)=\frac{p}{1-\eta^{2}}\left(1+\frac{r_{0}^{2}}{r^{2}}\right),
\end{aligned}
$$

where $p$ is the confining pressure, $R$ is the radius of the specimen, $r_{0}$ is the radius of the pore inside, and $r$ is the radius of one point at the cylinder. Meanwhile, $\eta$ equals $r_{0} / R$, $\sigma_{r}$ and $\sigma_{\theta}$ are tangential and radial stress, respectively.

When $r=r_{0}$, the inner wall stress of the specimen is

$$
\begin{aligned}
\sigma_{r} & =0, \\
\sigma_{\theta} & =\frac{2 p}{1-\eta^{2}} .
\end{aligned}
$$

When $r=R$, the outer wall stress of the specimen is

$$
\begin{aligned}
\sigma_{r} & =p, \\
\sigma_{\theta} & =p\left(\frac{2}{1-\eta^{2}}-1\right) .
\end{aligned}
$$

According to equations (1) and (2), $\sigma_{r}$ decreases as $r_{0}$ increases, while $\sigma_{\theta}$ increases as $r_{0}$ increases. Besides, $\sigma_{r}$ is smaller than $\sigma_{\theta}$ at each point of the specimen. The computation results show that the stress distribution of the thickwalled cylinder is not uniform under the triaxial compression.

Assuming that the failure of the thick-walled cylinder satisfies the Coulomb criterion [41], as the specimen is damaged, its bearing capacity just reaches the maximum value. The triaxial compressive strength can be expressed as $[55,56]$

$$
\sigma_{s}^{*}=\int_{r_{0}}^{R} 2 \pi r(Q+K r) \mathrm{d} r
$$

where $\sigma_{s}{ }^{*}$ is the triaxial compressive strength (TCS), Q and $K$ are the intercept and the slope of the linear correlation, respectively.

Substituting equation (1) into equation (5), we can get

$$
\sigma_{s}^{*}=\frac{\int_{r_{0}}^{R} 2 \pi r\left(Q+K P\left(P / 1-\eta^{2}\right)\left(1-\left(r_{0}^{2} / r^{2}\right)\right)\right) d r}{\pi\left(R^{2}-r_{0}^{2}\right)}=Q+K P f(\eta),
$$

where the detailed expression of $f(\eta)$ is

$$
f(\eta)=\frac{1}{1-\eta^{2}}\left(1+\frac{\eta^{2} \ln \eta^{2}}{1-\eta^{2}}\right)
$$

The relationship between $f(\eta)$ and $\eta$ is shown in Figure 4 . According to Figure $4, f(\eta)$ is always less than 1. Besides, the value of $\eta$ also changes with the pore size. Equation (6) indicates that $f(\eta)$ increases as the pore size reduces. When $Q, K$, and $P$ keep invariant, $\sigma_{s}{ }^{*}$ increases with the value of $f(\eta)$. The TCS is greater with the smaller pore size. Therefore, under the same confining pressure, the specimens with pore diameters of $10 \mathrm{~mm}, 15 \mathrm{~mm}$, and $20 \mathrm{~mm}$ show lower peak TCS than the complete sample.

The intermediate principal stress has a great influence on the strength of the rock specimens. According to the twin shear strength theory $[57,58]$, the intermediate principal stress $\sigma_{2}$ affects the peak TCS as follows:

$$
\sigma_{1}=K \frac{b \sigma_{2}+\sigma_{3}}{b+1}+Q
$$

In this formula, parameter $b$ indicates the influence of intermediate principal stress on the TCS of the specimens, the value of which ranges from 0 to 1 . When $b=1$, the influence reaches the maximum. By substituting equations (1) and (2) into equation (8), we can obtain the peak TCS at each point of the specimen as

$$
\sigma_{s}=K \frac{\sigma_{r}+\sigma_{\theta}}{2}+Q=\frac{K}{1-\eta^{2}} P+Q
$$




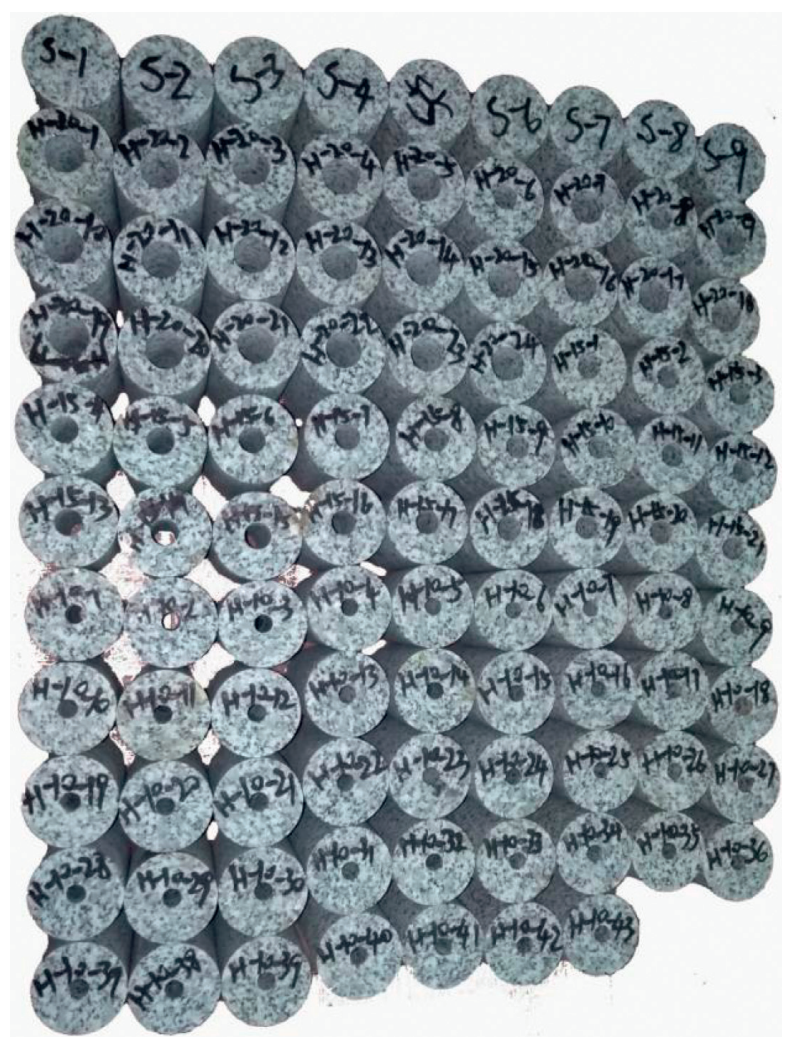

Figure 1: Thick-walled cylinder granite specimens.

Table 1: Detailed information about test specimens.

\begin{tabular}{|c|c|c|c|c|c|c|}
\hline Specimen number & Diameter (mm) & Height (mm) & Aperture $(\mathrm{mm})$ & Confining pressure $(\mathrm{MPa})$ & Elastic modulus (GPa) & $\begin{array}{c}\text { Axial pressure } \\
(\mathrm{MPa})\end{array}$ \\
\hline S-6 & 49.96 & 100.01 & 0 & 5 & 45.3 & 198.2 \\
\hline S-7 & 49.97 & 99.99 & 0 & 10 & 50.2 & 240.6 \\
\hline S-8 & 50.03 & 99.99 & 0 & 15 & 51.1 & 255.1 \\
\hline S-9 & 49.95 & 100.03 & 0 & 20 & 52.3 & 290.7 \\
\hline S-10 & 49.97 & 100.01 & 0 & 30 & 56.2 & 335.8 \\
\hline S-11 & 50.02 & 100.00 & 0 & 40 & 57.2 & 366.5 \\
\hline H-10-11 & 49.99 & 100.01 & 10.01 & 5 & 44.5 & 177.3 \\
\hline H-10-25 & 49.97 & 100.03 & 9.99 & 10 & 51.3 & 220.5 \\
\hline H-10-6 & 50.03 & 100.00 & 10.02 & 15 & 52.3 & 261.1 \\
\hline H-10-43 & 49.98 & 100.00 & 10.01 & 20 & 56.3 & 296.2 \\
\hline H-10-38 & 50.03 & 100.05 & 9.96 & 30 & 57.4 & 337.3 \\
\hline H-10-8 & 49.95 & 100.00 & 10.01 & 40 & 56.7 & 372.5 \\
\hline H-15-17 & 50.03 & 100.01 & 14.99 & 5 & 43.8 & 200.8 \\
\hline H-15-13 & 49.96 & 100.02 & 14.95 & 10 & 49.8 & 233.1 \\
\hline H-15-21 & 49.97 & 100.04 & 14.98 & 15 & 50.9 & 254.7 \\
\hline H-15-9 & 50.04 & 99.96 & 14.96 & 20 & 53.2 & 294.5 \\
\hline H-15-5 & 50.01 & 100.04 & 14.98 & 30 & 55.8 & 237.7 \\
\hline H-15-12 & 49.97 & 100.03 & 14.97 & 40 & 56.2 & 290.6 \\
\hline H-20-4 & 49.98 & 99.96 & 20.01 & 5 & 44.6 & 195.6 \\
\hline H-20-16 & 49.97 & 100.02 & 20.03 & 10 & 48.6 & 220.4 \\
\hline H-20-17 & 50.03 & 100.2 & 19.95 & 15 & 50.7 & 248.3 \\
\hline H-20-5 & 49.99 & 99.96 & 20.04 & 20 & 54.3 & 280.5 \\
\hline H-20-8 & 50.04 & 100.03 & 19.98 & 30 & 52.6 & 336.2 \\
\hline H-20-19 & 49.96 & 99.97 & 20.02 & 40 & 56.8 & 300.7 \\
\hline
\end{tabular}

According to equation (9), the peak TCS of each point on the inner wall has no relation with its radial position. It is only related to the ratio of internal and external pore sizes.
Therefore, if the friction effect of the material is constant and the confining pressure keeps the same, the axial bearing capacity of the cylinder will be higher than that of the 


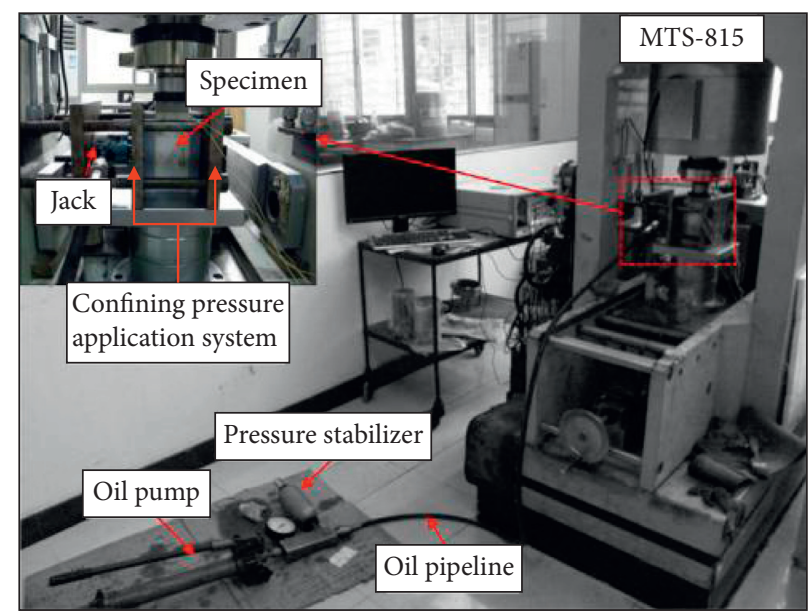

(a)

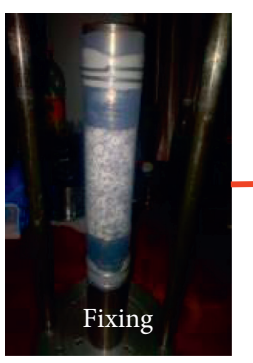

(b)

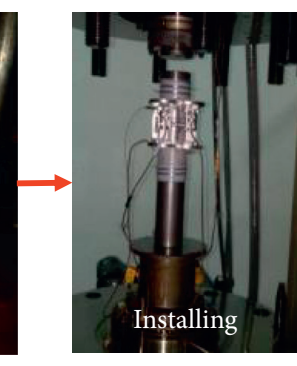

(c)

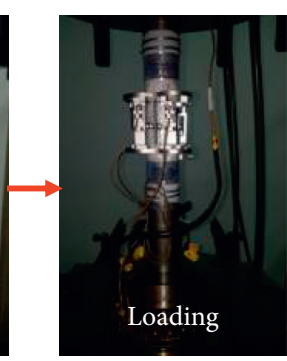

(d)

Figure 2: Triaxial compression test process. (a) MTS-815 testing system. (b) Sample fixing. (c) Sample installing. (d) Sample loading.

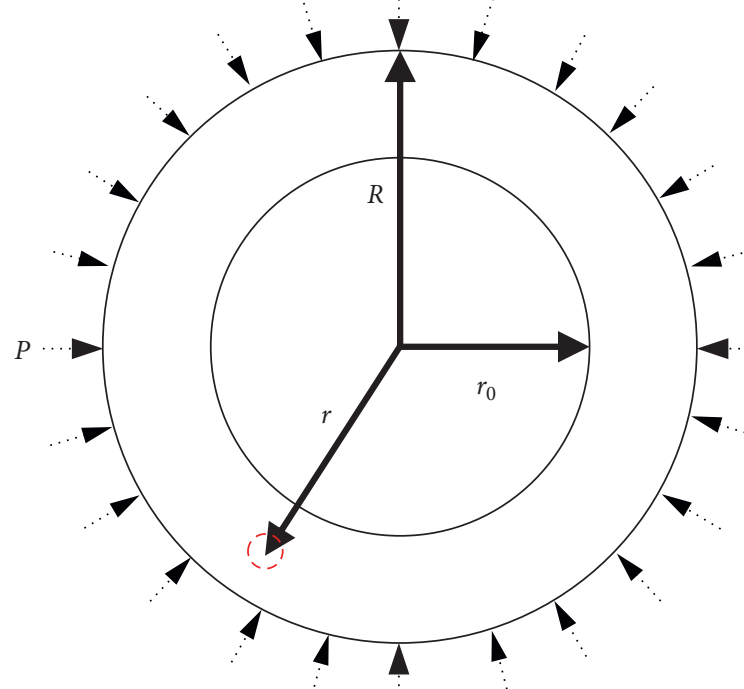

(a)

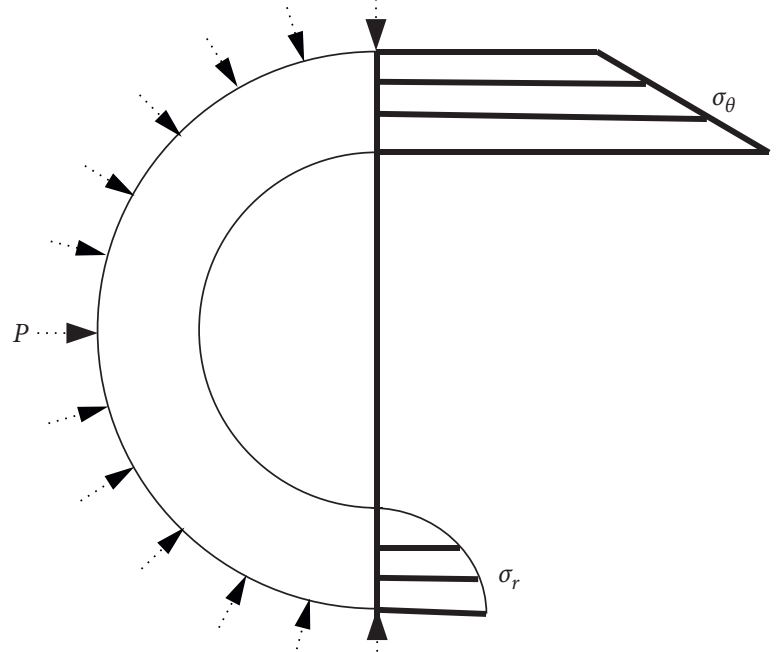

(b)

FIgURE 3: The stress distribution of the thick-walled cylinder under confining pressure.

complete specimen. However, the test results are not the same as the predictions in equations (6) and (9).

3.1.2. Stress Analysis on Complete Cylinder. Under conventional triaxial compression, the internal stress is the same at each point of the complete cylinder, and follows the
Mohr-Coulomb criterion [41]. When the specimen loses its bearing capacity, shear fracture occurs. Figure 5 shows the macroscopic fracture surface. $\theta$ denotes the angle between the direction of the maximum principal stress and the normal direction of the shear plane. According to the Mohr stress circle theory [59], the normal stress $\sigma$ and shear stress $\tau$ of fractured surface are 


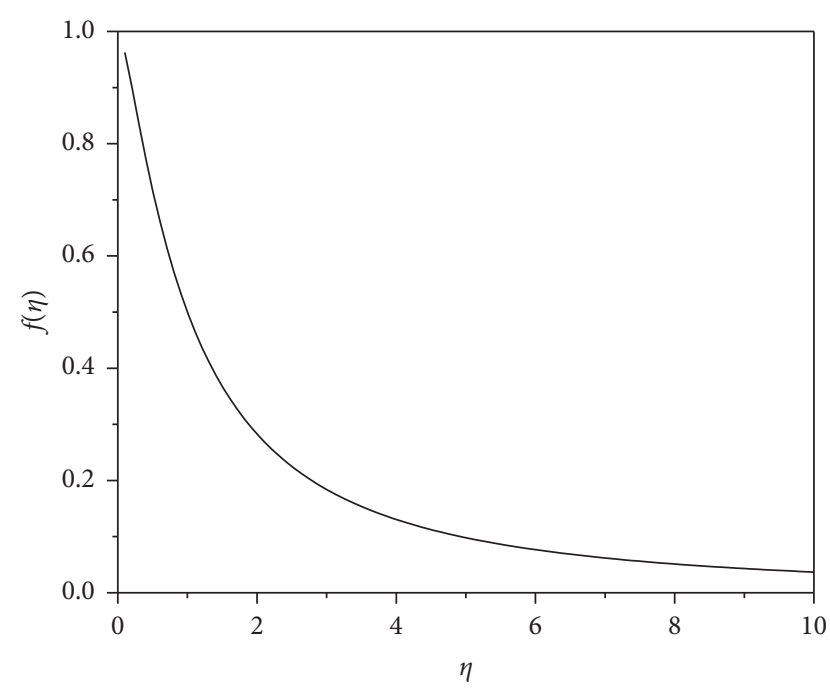

FIgURE 4: The relationship between $f(\eta)$ and $\eta\left(\eta=r_{0} / R\right)$.

$$
\begin{aligned}
& \sigma=\frac{\left(\sigma_{1}+\sigma_{3}\right)}{2}+\frac{\left(\sigma_{1}-\sigma_{3}\right) \cos 2 \theta}{2}, \\
& \tau=\frac{\left(\sigma_{1}-\sigma_{3}\right) \sin 2 \theta}{2}, \\
& \tau=C+\sigma \tan \phi
\end{aligned}
$$

where $C$ and $\varphi$ are the cohesion and the internal friction angle, respectively. The maximum principal stress $\sigma_{1}$ and the minimum principal stress $\sigma_{3}$ on the fractured surface satisfy the following equation:

$$
\frac{\left(\sigma_{1}-\sigma_{3}\right) / 2}{C \cot \phi+\left(\sigma_{1}+\sigma_{3}\right) / 2}=\sin \phi .
$$

On the cross section with " $\theta=45^{\circ}+\phi / 2$ ", there is

$$
\sigma_{1}=\frac{2 C \cos \phi}{1-\sin \phi}+\frac{1+\sin \phi}{1-\sin \phi} \sigma_{3} .
$$

The Coulomb criterion [41] can be expressed with the principal stress $\sigma_{3}$ as

$$
\sigma_{s}=Q+K \sigma_{3}
$$

where $Q$ and $K$ are the parameters of the strength criterion [41]. They are related to $C$ and $\varphi$.

$$
\begin{aligned}
& K=\tan ^{2} \theta_{0}, \\
& Q=2 C \tan \theta_{0} .
\end{aligned}
$$

\subsection{Deformation of Thick-Walled Cylinder under Triaxial Compression}

3.2.1. Influence of Confining Pressure on Deformation. Figure 6 shows the triaxial compression stress-strain curve under different confining pressures. For each pore size, the granite specimens all show brittle failure states, and there is no obvious yield stage. In general, the peak TCS increases significantly with the confining pressure.

According to Figure 6, the partial stress-axial strain curve can be divided into five stages [60, 61]: (1) Compression and closure stage of the primary flaws. (2) Linear elasticity deformation stage. (3) Stable development stage of cracks, in which new micro-cracks appear and expand stably with the axial stress. (4) Unstable growth stage of the cracks, the stress threshold of which corresponds to the initial fracture. In this stage, penetrated cracks appear and the volume begins to expand. With an increase of the axial stress, the main stress intensity reaches its peak value. Then, the macro penetrated cracks appear and the rock is damaged. (5) After reaching the peak TCS, the stress drops obviously. The specimen shows a characteristic of brittle failure, yet it maintains residual strength due to the constraint of the confining pressure. As MTS-815 has a post-peak confining pressure maintaining system, the stress-strain curves are relieved after the rapid drop. Although the axial stress drops to a lower level after the peak value, the confining pressure remains unchanged. Under the continuous confining pressure, the fractured surface is occluded until the shear strength is reached.

3.2.2. Influence of Aperture on Deformation. For the specimens with different pore sizes, we finally selected the successful test results. Figure 7 shows their stress-strain curves under the same confining pressure. In general, when the pore size is $0 \mathrm{~mm}$ or $10 \mathrm{~mm}$, the specimen has the maximum peak TCS under various confining pressures. When the confining pressure is no larger than $20 \mathrm{MPa}$, there is little difference in the peak TCS between the complete specimens and the ones with pores. When the confining pressure reaches $30 \mathrm{MPa}$, the peak TCS of the specimen with a pore diameter of $15 \mathrm{~mm}$ is lower than the others. When the confining pressure reaches $40 \mathrm{MPa}$, the peak TCS of the specimens with $15 \mathrm{~mm}$ or $20 \mathrm{~mm}$ pore diameter are significantly lower than that of the others. To conclude, if the confining pressure is greater, the peak TCS difference between the specimens with different pore sizes will be larger.

\subsection{Strength of Thick-Walled Cylinder under Triaxial Compression}

3.3.1. Relationship between TCS and Confining Pressure. To study the relationship between TCS and the confining pressure of thick-walled cylinder granites, this paper draws the deviator stress $\left(\sigma_{1}-\sigma_{3}\right)$ curves under six different confining pressures through linear fitting (see Figure 8(a)).

$$
\sigma_{1}-\sigma_{3}=K \sigma_{3}+Q
$$

where $\sigma_{1}$ is TCS, and $\sigma_{3}$ is the confining pressure. $K$ and $Q$ are fitting coefficients.

Table 2 shows the fitting results. When the confining pressure is within $5 \sim 20 \mathrm{MPa}$, the fitting coefficient $R^{2}$ is above 0.96, which indicates that the deviator stress curve can be fitted linearly (see Figure $8(\mathrm{~b})$ ). For complete cylinders meeting the Coulomb criterion [41], the cohesion $C$ and 


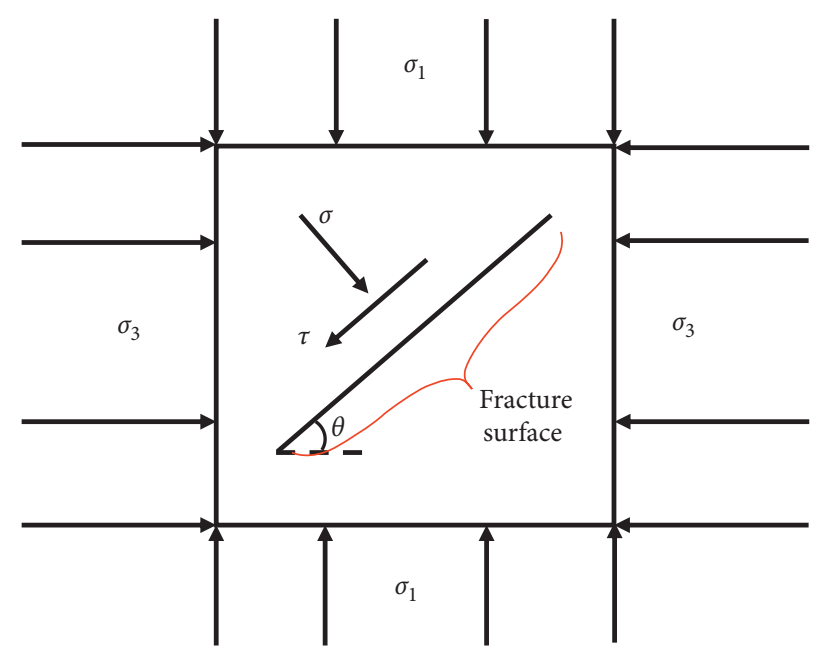

(a)

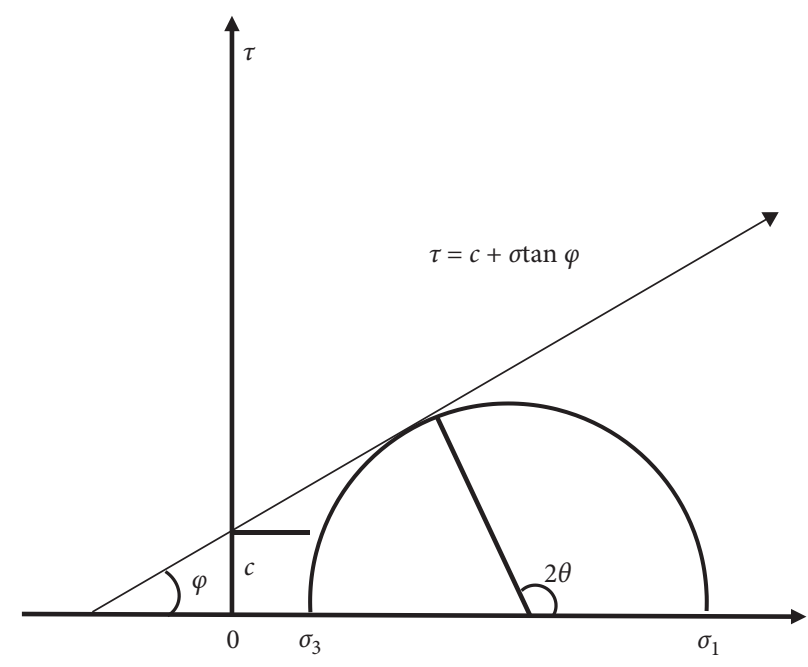

(b)

FIgURE 5: Stress analysis diagram of fractured rock mass under triaxial compression. (a) Fractured surface. (b) Mohr-Coulomb failure criterion.

internal friction angle $\varphi$ have to satisfy the following relationships with $K$ and $Q$ :

$$
\begin{gathered}
\varphi=\arcsin \frac{K-1}{K+1}, \\
C=\frac{(1-\sin \phi)}{2 \cos \phi} Q .
\end{gathered}
$$

Taking the fitting parameters into account, we can work out the values of $C$ and $\varphi$, and make further analysis on the fracture angle. In Table 2, the parameter of $\sigma_{3}$ is $K f(\eta)$. For the thick-walled cylinders with pore diameters of $10 \mathrm{~mm}$, $15 \mathrm{~mm}$, and $20 \mathrm{~mm}$, their $f(\eta)$ are $0.902,0.837$, and 0.775 , respectively.

According to the fitting results, $C$ and $\varphi$ are different between the complete and the thick-walled cylinders. $C$ increases with pore size, while $\varphi$ decreases with it. This phenomenon is due to the existence of pores. It makes the stress states different at each point of the specimen. During the compression process, the inner wall of the specimen is damaged first. With an increase of axial loading, the specimen fails from inside to outside. Finally, the whole specimen loses its bearing capacity. Note that $\sigma_{1}$ has a great influence on the failure. Therefore, the Coulomb criterion [41] is only applicable to the measurement of $C$ and $\varphi$ of the complete specimens but not to the thick-walled cylinders.

3.3.2. Relationship between TCS and Pore Size. Figure 9 shows the fitting relationship between TCS and pore size. Under the same confining pressure, the peak TCS generally shows a decreasing trend with an increase of pore size. However, when the confining pressure is small enough (5 $\mathrm{MPa}$ and $10 \mathrm{MPa})$, this rule is not obvious.

\subsubsection{Relationship between Elastic Modulus and Confining} Pressure. As shown in Figure 10(a), the elastic modulus of the complete and the thick-walled specimens ranges from
$40 \mathrm{GPa}$ to $60 \mathrm{GPa}$ under triaxial compression. The dispersion degree of the elastic modulus is small. When the pore size keeps, the elastic modulus increases as the confining pressure increases.

3.3.4. Relationship between Elastic Modulus and Aperture. Fitting curves between the elastic modulus and the aperture of the thick-walled cylinders are shown in Figure 10(b). It shows that the pore size has little influence on the elastic modulus, which means that they are not correlated.

3.4. Failure Mode of Thick-Walled Cylinders under Triaxial Compression. To study the influence of confining pressure on the failure mode, we carry out their failure modes in Figure 11. The macro failure mode of thick-walled cylinder granites includes shear and splitting failure. When the confining pressure is low, the failure mode is mainly the shear failure. With an increase in the confining pressure, the splitting failure appears. When axial stress reaches peak TCS, it breaks and makes a crisp sound. At this time, the typical characteristics of brittle failure appear.

It can be seen from Figures 11(a), 11(b), 11(e), 11(f), 11(i), 11(j), 11(m), and 11(n) that the angles between the splitting fractures and the horizontal plane decrease with the reduction of confining pressure. Moreover, in Figures 11(c), 11(d), 11(g), 11(h), 11(k), 11(l), 11(o), and 11(p), the angles between the shear fractures and the horizontal plane also decrease at lower confining pressure. For the specimen with the same pore size, if the confining pressure is lower, the fractured area will also be smaller.

In conclusion, both confining pressure and pore size have significant influences on the internal failure characteristics of thick-walled cylinder granites. In the initial stage of loading, the intermediate stress inside the specimen is the axial stress. With an increase of the axial loading, the maximum principal stress on the specimen changes from 


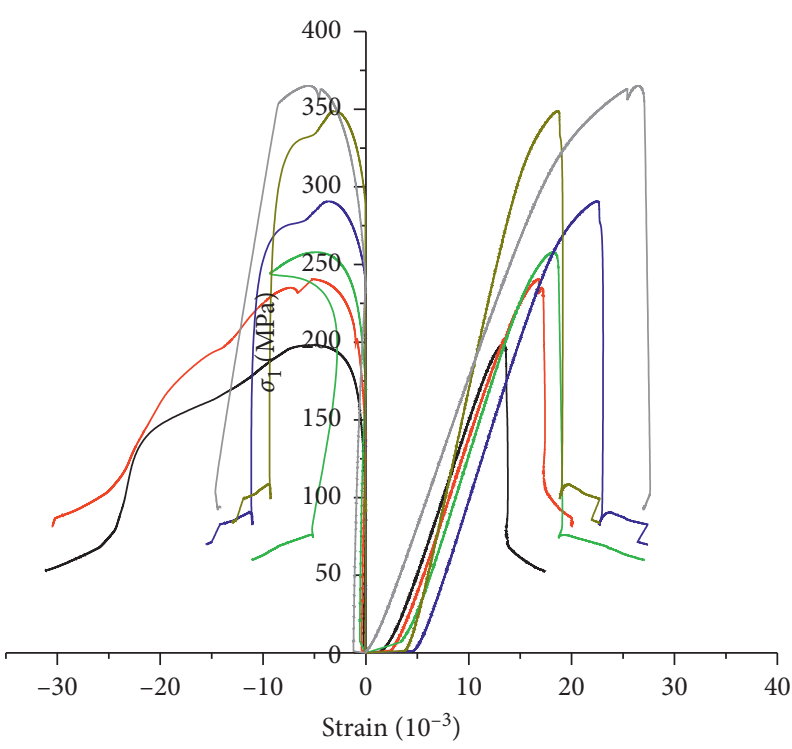

Volume strain

$\sigma_{3}=5 \mathrm{MPa}$

$-\sigma_{3}=10 \mathrm{MPa}$

$-\sigma_{3}=15 \mathrm{MPa}$

$-\sigma_{3}=20 \mathrm{MPa}$

$-\sigma_{3}=30 \mathrm{MPa}$

- $\sigma_{3}=40 \mathrm{MPa}$
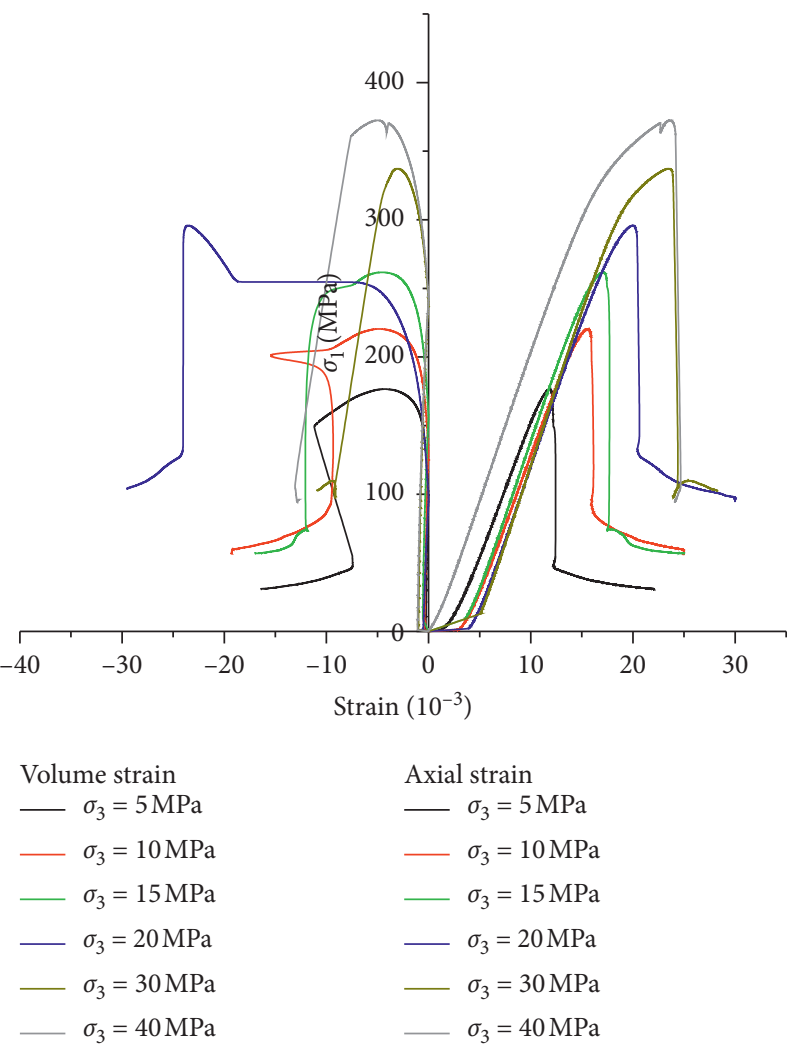

Axial strain

$-\sigma_{3}=5 \mathrm{MPa}$

$-\sigma_{3}=10 \mathrm{MPa}$

$-\sigma_{3}=15 \mathrm{MPa}$

$-\sigma_{3}=20 \mathrm{MPa}$

$-\sigma_{3}=30 \mathrm{MPa}$

- $\sigma_{3}=40 \mathrm{MPa}$

(b) (a)

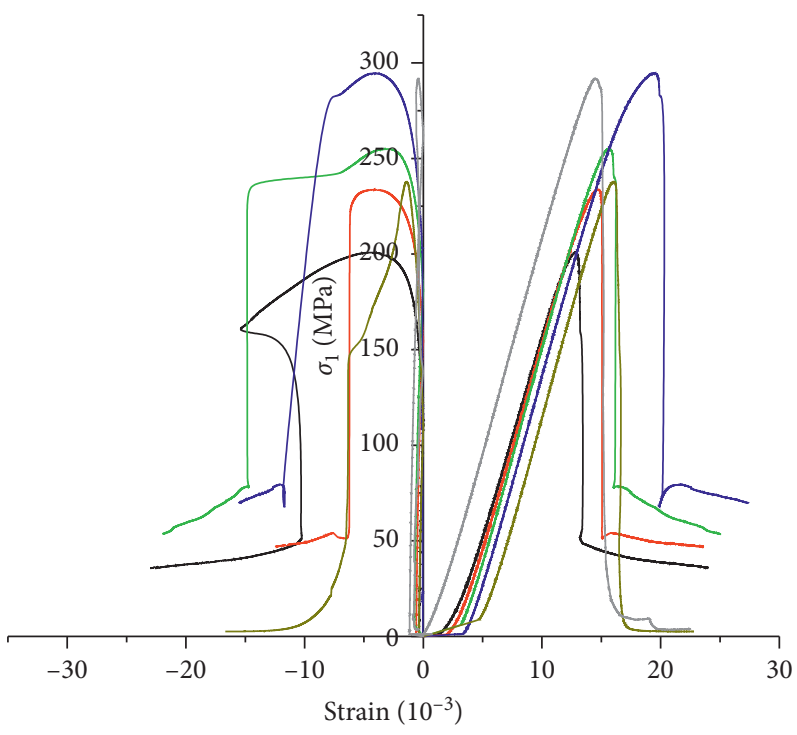

Axial strain

$-\sigma_{3}=5 \mathrm{MPa}$

- $\sigma_{3}=10 \mathrm{MPa}$

$-\sigma_{3}=15 \mathrm{MPa}$

$-\sigma_{3}=20 \mathrm{MPa}$

$-\sigma_{3}=30 \mathrm{MPa}$

$\sigma_{3}=40 \mathrm{MPa}$

(c)

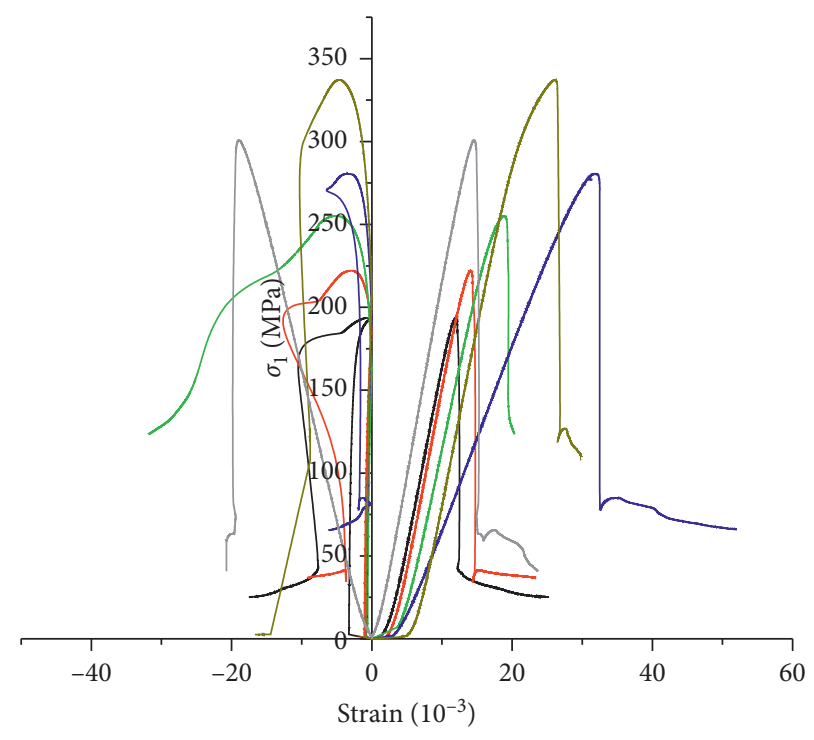

Volume strain

$-\sigma_{3}=5 \mathrm{MPa}$

$-\sigma_{3}=10 \mathrm{MPa}$

$-\sigma_{3}=15 \mathrm{MPa}$

$-\sigma_{3}=20 \mathrm{MPa}$

$-\sigma_{3}=30 \mathrm{MPa}$

$-\sigma_{3}=40 \mathrm{MPa}$

$$
\begin{aligned}
& \text { Axial strain } \\
& -\sigma_{3}=5 \mathrm{MPa} \\
& -\sigma_{3}=10 \mathrm{MPa} \\
& -\sigma_{3}=15 \mathrm{MPa} \\
& -\sigma_{3}=20 \mathrm{MPa} \\
& -\sigma_{3}=30 \mathrm{MPa} \\
& \sigma_{3}=40 \mathrm{MPa}
\end{aligned}
$$

(d)

Figure 6: Triaxial compression stress-strain curves of the specimens under different confining pressures. (a) Pore size is 0 mm. (b) Pore size is $10 \mathrm{~mm}$. (c) Pore size is $15 \mathrm{~mm}$. (d) Pore size is $20 \mathrm{~mm}$. 

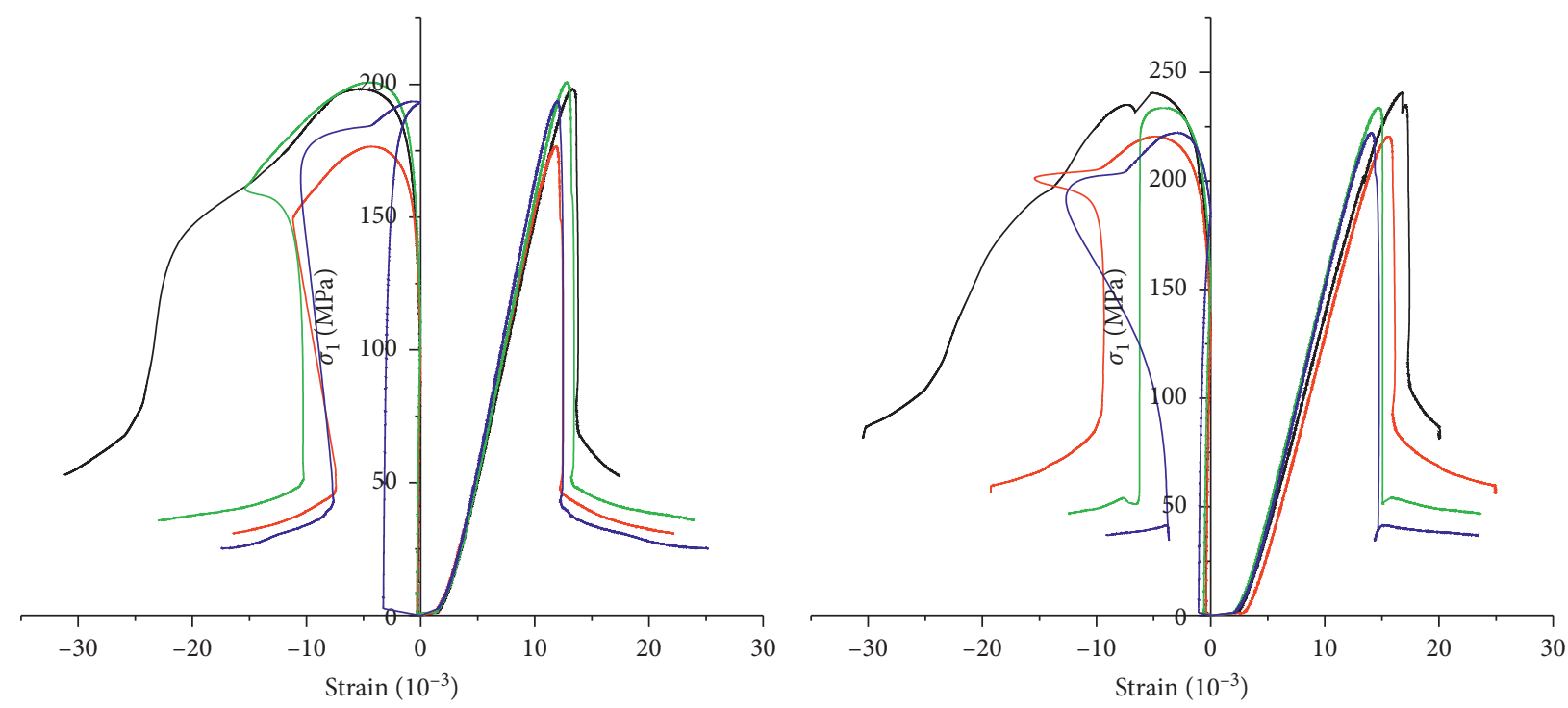

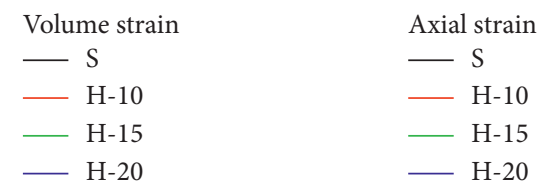

(a)
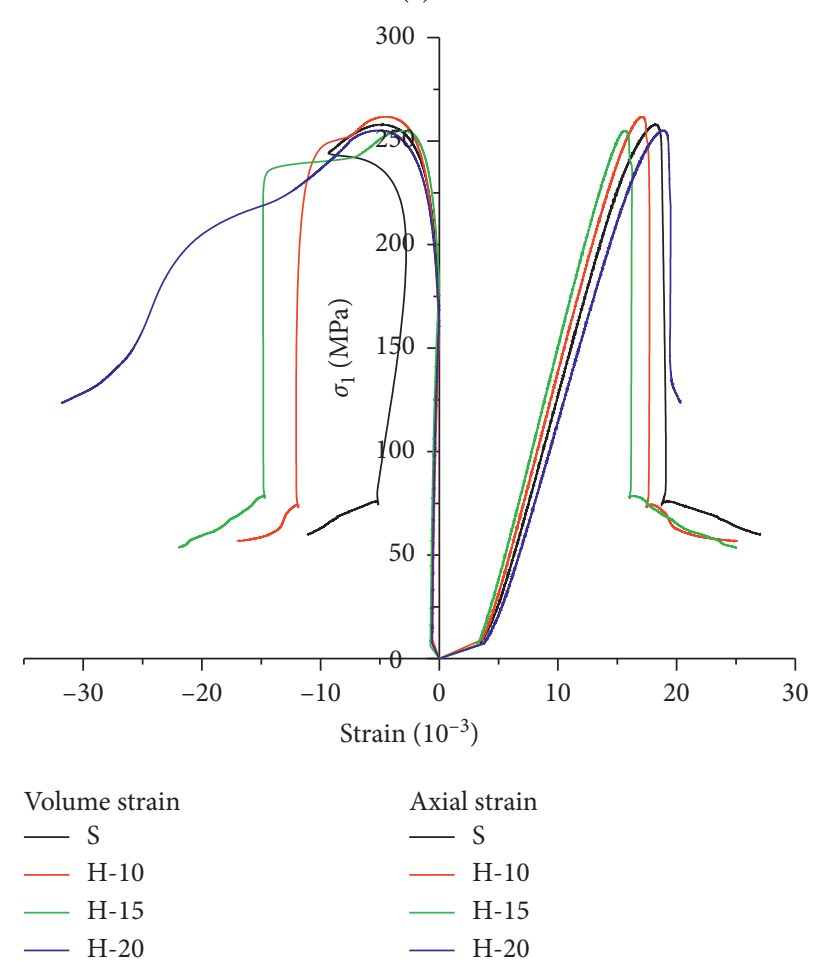

(c)

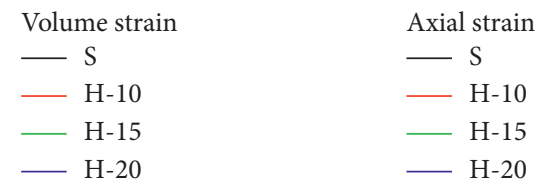

(b)

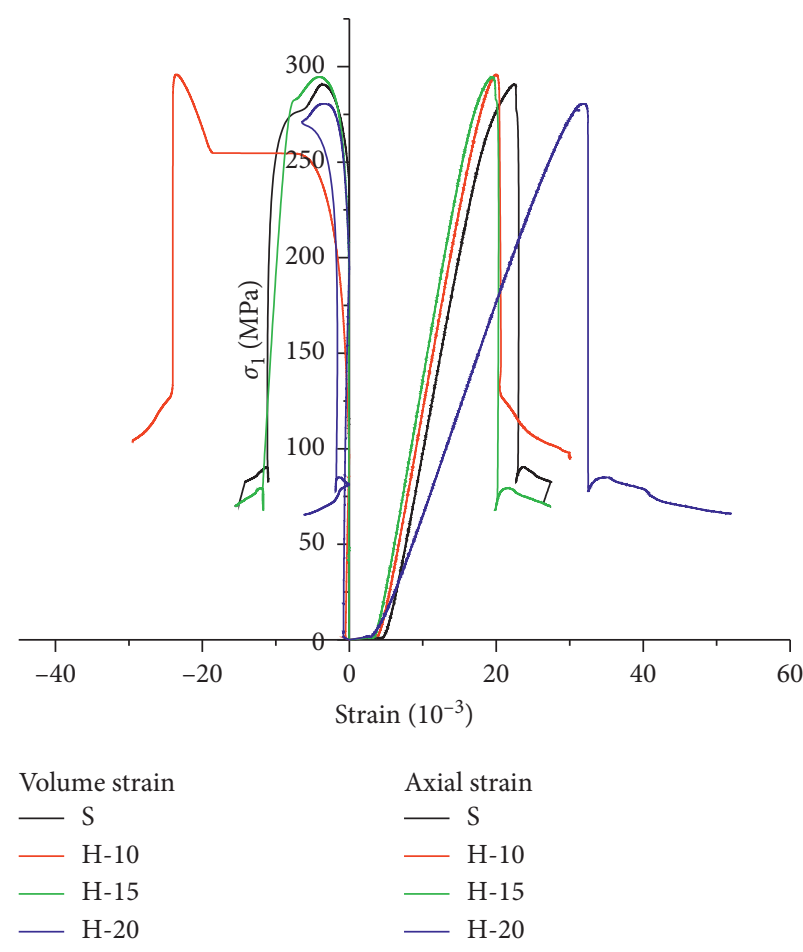

(d)

Figure 7: Continued. 

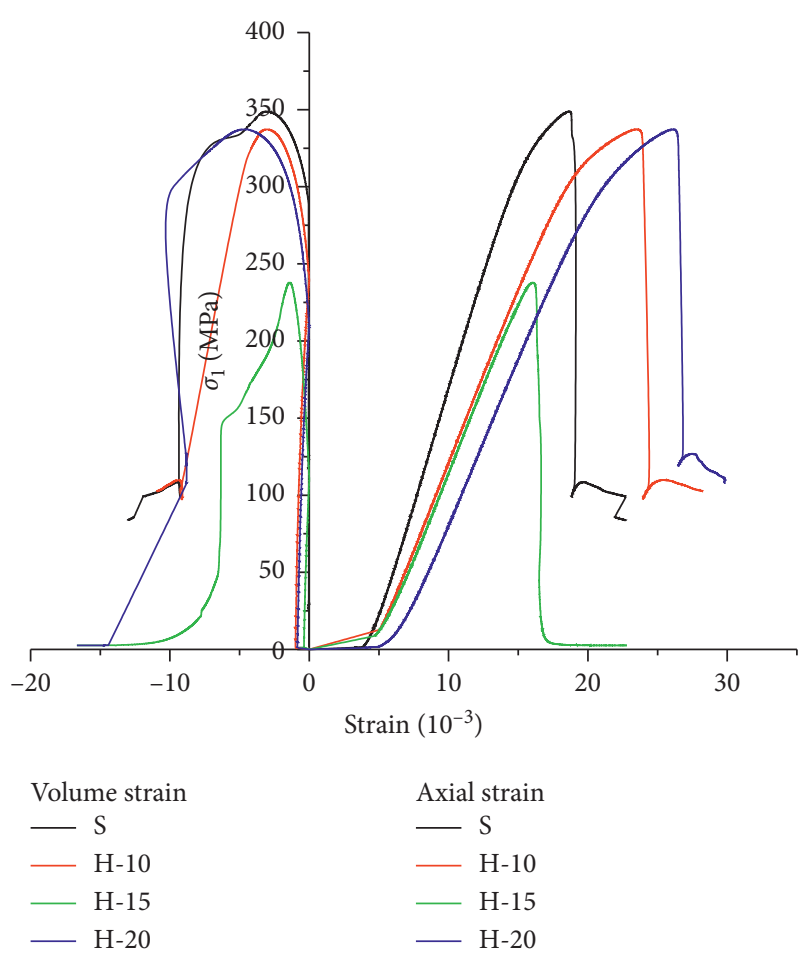

(e)
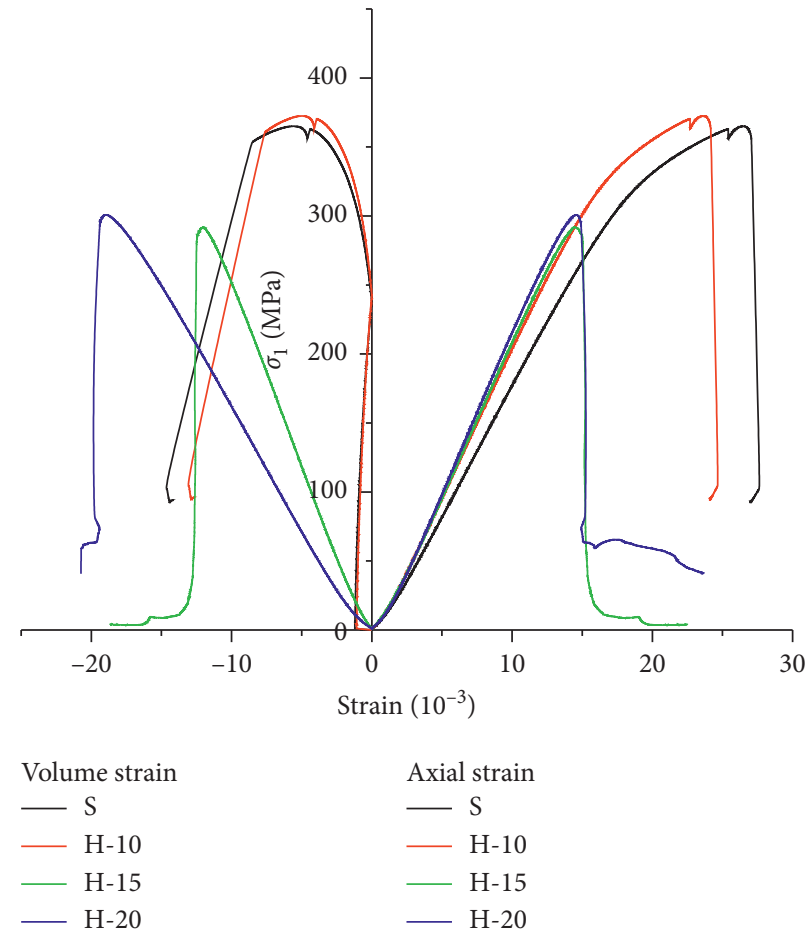

(f)

Figure 7: Triaxial compression stress-strain curve of the specimens with different pore sizes. (a) Confining pressure is $5 \mathrm{MPa}$. (b) Confining pressure is $10 \mathrm{MPa}$. (c) Confining pressure is $15 \mathrm{MPa}$. (d) Confining pressure is $20 \mathrm{MPa}$. (e) Confining pressure is $30 \mathrm{MPa}$. (f) Confining pressure is $40 \mathrm{MPa}$.

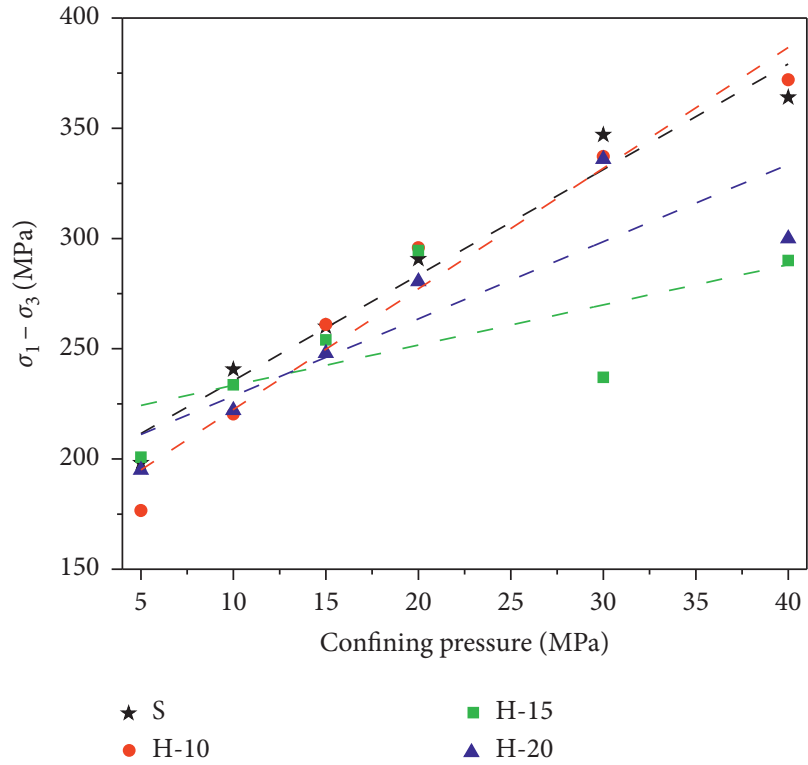

(a)

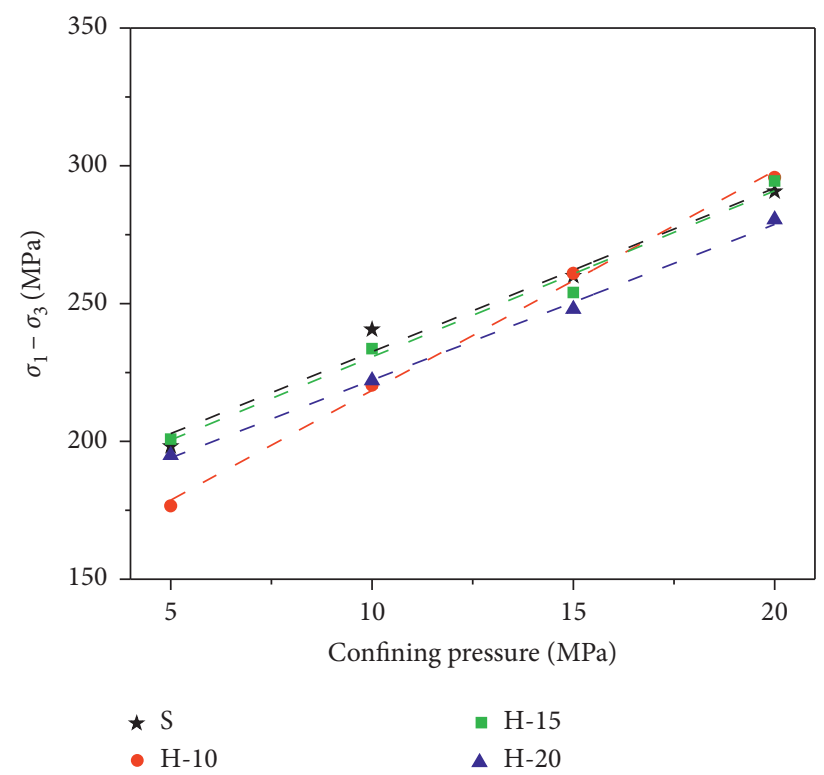

(b)

FIGURE 8: Fitting curves of the confining pressure and the deviator stress of specimens with different pore sizes. (a) Fitting curves under confining pressures $(5 \sim 40 \mathrm{MPa})$. (b) Fitting curves under four different confining pressures $(5 \sim 20 \mathrm{MPa})$.

tangential to axial. Because the minimum principal stress on the inner wall is low, it is damaged first. Then, the fractures extend to the outer wall of the specimen.
3.5. Parameter Analysis on Hoek-Brown Criterion. Hoek-Brown strength criterion [42] is one of the most widely used rock failure criteria. Since the time it was put 
TABLE 2: The linear fitting results of confining pressures (5 20 MPa).

\begin{tabular}{lccccr}
\hline$d(\mathrm{~mm})$ & $K$ & $Q(\mathrm{MPa})$ & $R^{2}$ & $\phi\left(^{\circ}\right)$ & $C(\mathrm{MPa})$ \\
\hline 0 & 5.42 & 177.67 & 0.9925 & 43.51 & 38.16 \\
10 & 4.87 & 182.34 & 0.9727 & 41.25 & 41.31 \\
15 & 4.65 & 183.46 & 0.9618 & 40.24 & 42.54 \\
20 & 4.35 & 180.26 & 0.9677 & 38.77 & 65.63 \\
\hline
\end{tabular}

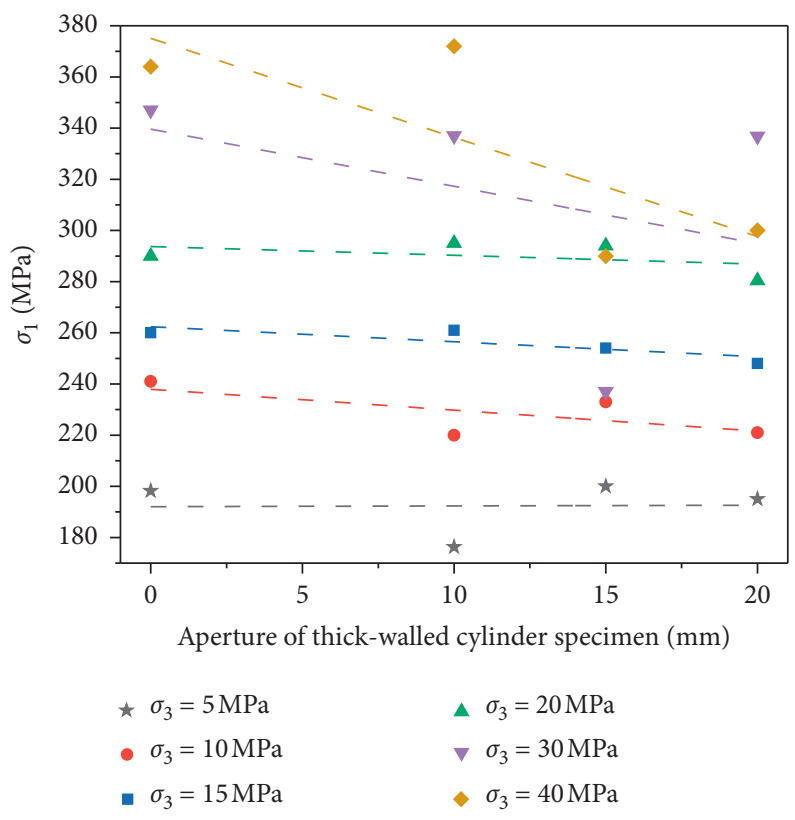

Figure 9: Fitting curves between the aperture and peak TCS.

forward, scholars have made continuous improvements. In 1965, Hoek proposed its initial model through lots of indoor triaxial compression experiments. Then, Hoek and Brown put forward the nonlinear Hoek-Brown rock failure criterion based on data fitting $[42,62]$ :

$$
\sigma_{1}=\sigma_{3}+\sigma_{c}\left(m_{b} \frac{\sigma_{3}}{\sigma_{c}}+1\right)^{0.5}
$$

where $\sigma_{1}$ and $\sigma_{3}$ denote the maximum and the minimum principal stress, respectively. $\sigma_{c}$ is the uniaxial compressive strength, and $m_{b}$ is the model parameter. The original generalized Hoek-Brown failure criterion can be expressed as $[63,64]$

$$
\sigma_{1}=\sigma_{3}+\sqrt{m \sigma_{c} \sigma_{3}+s \sigma_{c}^{2}}
$$

where $m$ and $s$ are model parameters.

With the development of the engineering construction, Hoek and Brown proposed the generalized HoekBrown failure criterion in 1980 to solve engineering problems. The criterion is an empirical one about the nonlinear failure of rocks. It is derived by fitting strength data in the two-dimensional space [62]:

$$
\sigma_{1}^{\prime}=\sigma_{3}^{\prime}+\sigma_{c}\left(m_{b} \frac{\sigma_{3}^{\prime}}{\sigma_{c}}+s\right)^{a} .
$$

$\sigma_{c}$ is the uniaxial compressive strength of the rock. $\sigma_{1}{ }^{\prime}$ and $\sigma_{3}{ }^{\prime}$ are the maximum and the minimum effective principal stresses. $a$ is a constant. $m_{b}$ and $s$ are constants of the rock material. The constant expressions are as follows $[63,64]$ :

$$
\begin{aligned}
m_{b} & =m_{i} \exp \left(\frac{\mathrm{GSI}-100}{28-14 D}\right), \\
S & =\exp \left(\frac{\mathrm{GSI}-100}{9-3 D}\right), \\
a & =\frac{1}{2}+\frac{1}{6}\left(e^{-(\mathrm{GSI} / 15)}-e^{-(20 / 3)}\right) .
\end{aligned}
$$

Since the discontinuous rock structure and the surface weathering condition can affect the quality of the in-situ rock mass, the above expression introduces the parameter GSI. Hoek pointed out that the value of GSI ranges from 10 to 100 . "GSI $=10$ " indicates that the rock mass is extremely poor while "GSI $=100$ " indicates the rock is complete $[63,64]$. The parameter $D$ is a disturbance factor reflecting the degree of rock disturbance. In an undisturbed rock mass, $D$ is 0 . When the rock mass is extremely affected by blasting damage and stress relaxation, $D$ is 1 . The model parameter $m_{i}$ is obtained from the simulation and experience, similar to the friction strength of the complete rock. The model parameter $m_{b}$ is also affected by GSI and $D$. 


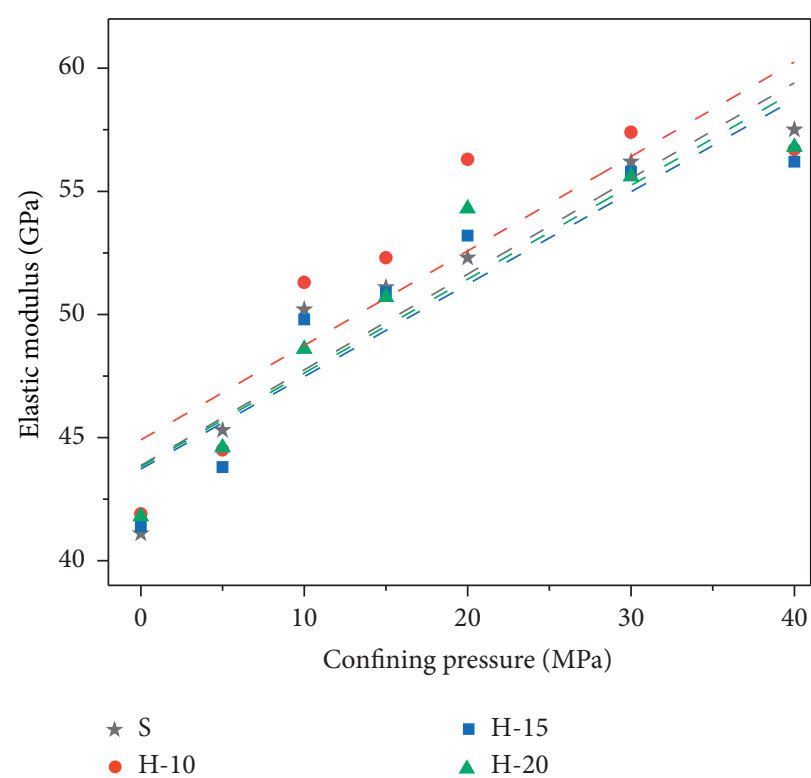

(a)

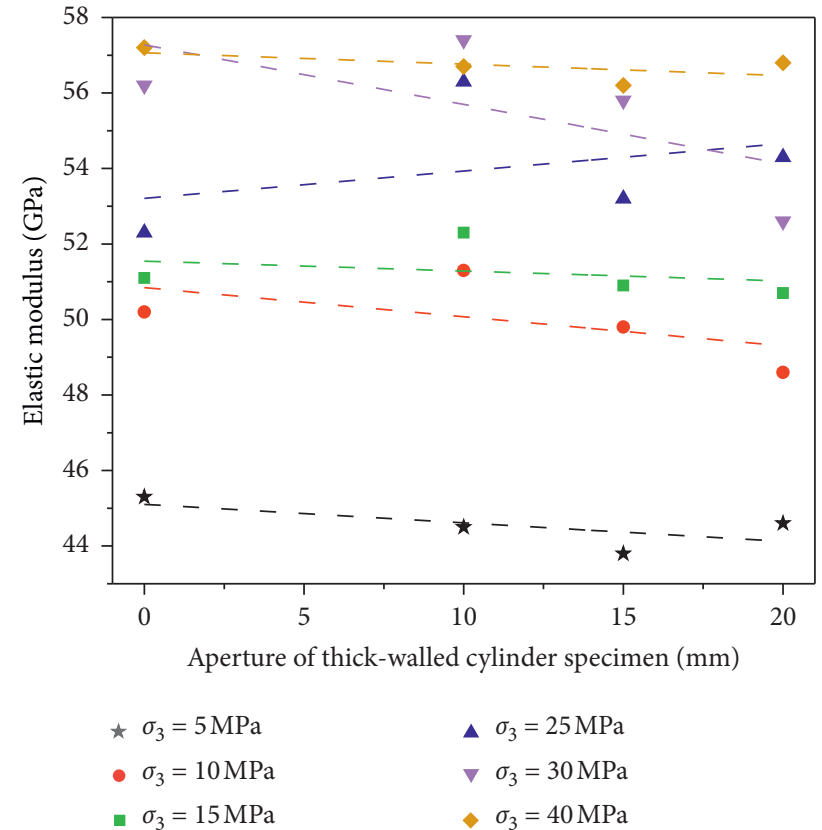

(b)

Figure 10: Elastic modulus diagram. (a) Fitting curves between confining pressure and elastic modulus. (b) Fitting curves between apertures and elastic modulus.

For a complete rock mass, $D=0, \mathrm{GSI}=100, S=1 . S$ is related to the fracture degree of the rock, which reflects the cohesion. $m$ is related to the occlusion degree among rock particles. Its value is high for the complete rock, and decreases when the damage increases. Therefore, the HoekBrown strength criterion is $[63,64]$

$$
\sigma_{1}^{\prime}=\sigma_{3}^{\prime}+\sigma_{c}\left(m_{b} \frac{\sigma_{3}^{\prime}}{\sigma_{c}}+1\right)^{0.5} .
$$

In Hoek and Brown's point of view, the parameter $m_{i}$ of a complete rock is approximate to the ratio between its uniaxial compressive strength and uniaxial tensile strength. Therefore, the empirical value of $m_{i}$ can be obtained through the curve fitting of the test data [65]. In the absence of test data, the compressive strength of the rocks can be determined according to the experience table provided by Hoek et al. [63, 64]. In 2011, Read and Richards [69] studied the parameter selection method of the Hoek-Brown yield criterion [70], and determined the parameters based on a large number of experimental data. They pointed out that without data from the triaxial compression tests, it is also feasible to determine the parameter $m_{i}$ with $R=\sigma_{c} / \sigma_{t}$. In 2010, Cai [71] did further research on the Hoek-Brown failure criterion of strong brittle intact rock and studied its parameters based on the Griffith theory [35-37]. He represented the parameters with the uniaxial compressive strength, crack initiation strength, and confining pressure, and finally worked out a calculation formula for $m_{i}$ in the brittle rocks. Note that this method considers the influence of the confining pressure on $m_{i}$.

3.6. Parameter Analysis on Three-Dimensional Hoek-Brown Strength Criterion. Since the Hoek-Brown strength criterion ignores the effect of intermediate principal stress [63, 64], Zhang and Zhu [49] proposed the three-dimensional HoekBrown strength criterion:

$$
\frac{9}{2 \sigma_{c}} \tau_{\mathrm{oct}}^{2}+\frac{3}{2 \sqrt{2}} m \tau_{\mathrm{oct}}-\sigma_{m, 2}^{\prime}=s \sigma_{c},
$$

where $\sigma_{m, 2}^{\prime}$ and $\tau_{\text {oct }}$ are the effective mean stress and the octahedral shear stress, respectively.

$$
\begin{aligned}
S & =1, \\
\sigma_{3} & =\sigma_{r}=\frac{R^{2} P}{R^{2}-r_{0}^{2}}\left(1-\frac{r_{0}^{2}}{r^{2}}\right)=\frac{P}{1-\eta^{2}}\left(1-\frac{r_{0}^{2}}{r^{2}}\right), \\
\sigma_{2} & =\sigma_{\theta}=\frac{R^{2} P}{R^{2}-r_{0}^{2}}\left(1+\frac{r_{0}^{2}}{r^{2}}\right)=\frac{P}{1-\eta^{2}}\left(1+\frac{r_{0}^{2}}{r^{2}}\right), \\
\sigma_{m, 2}^{\prime} & =\frac{\sigma_{1}+\sigma_{3}}{2}, \\
\tau_{\mathrm{oct}} & =\frac{1}{3} \sqrt{\left(\sigma_{1}-\sigma_{2}\right)^{2}+\left(\sigma_{2}-\sigma_{3}\right)^{2}+\left(\sigma_{1}-\sigma_{3}\right)^{2}} .
\end{aligned}
$$

Then, 


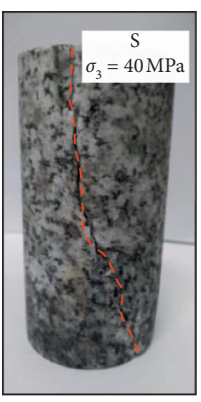

(a)

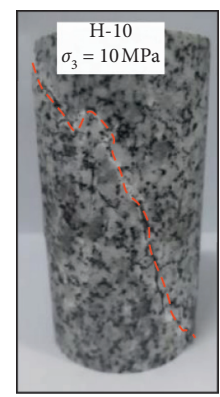

(g)

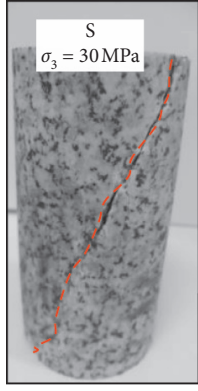

(b)

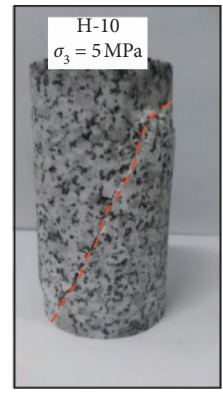

(h)

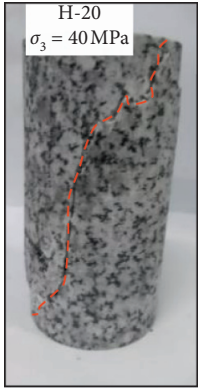

(m)

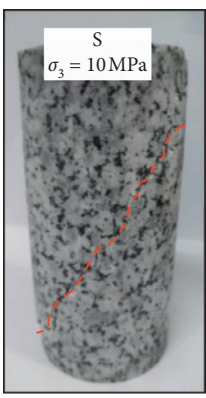

(c)

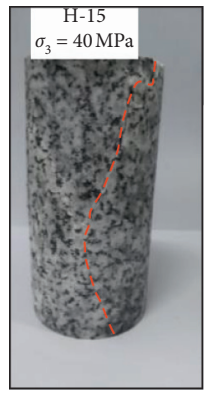

(i)

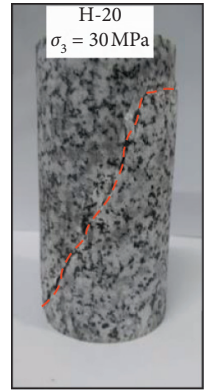

(n)

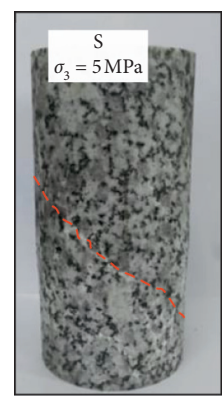

(d)

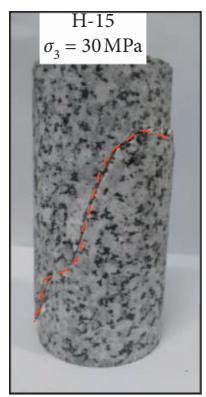

(j)

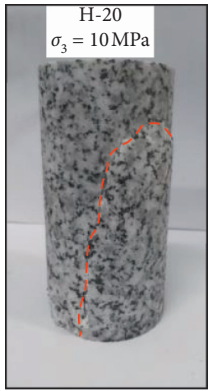

(o)

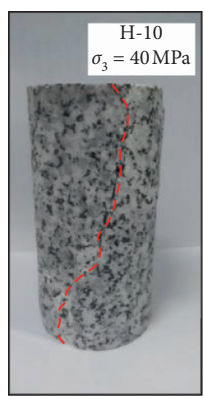

(e)

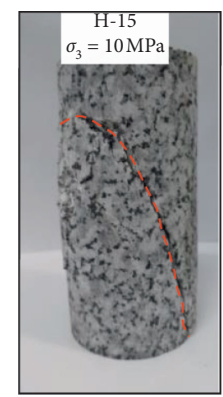

$(\mathrm{k})$

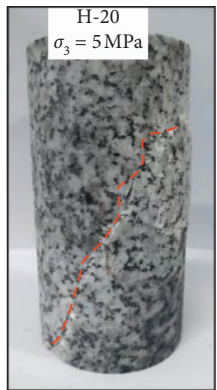

(p)

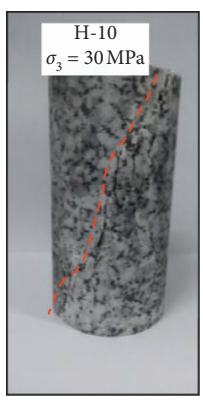

(f)

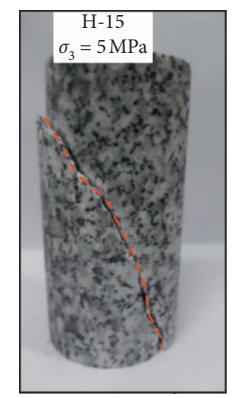

(1)

Figure 11: Typical failure modes of granite specimens.

$m=\frac{\sigma_{c}-\left(9 / 2 \sigma_{c}\right) \tau_{\mathrm{oct}}^{2}}{\left(3 \tau_{\mathrm{oct}} / 2 \sqrt{2}\right)-\sigma_{m, 2}^{\prime}}$

$m=\frac{\sigma_{c}-\left(1 / 2 \sigma_{c}\right) \sqrt{\left(\sigma_{1}-\sigma_{2}\right)^{2}+\left(\sigma_{2}-\sigma_{3}\right)^{2}+\left(\sigma_{1}-\sigma_{3}\right)^{2}}}{(1 / 2 \sqrt{2}) \sqrt{\left(\sigma_{1}-\sigma_{2}\right)^{2}+\left(\sigma_{2}-\sigma_{3}\right)^{2}+\left(\sigma_{1}-\sigma_{3}\right)^{2}}-\sigma_{m, 2}^{\prime}}$.

It can be further simplified as

$$
m=\frac{\sigma_{c}-\left(1 / 2 \sigma_{c}\right) n}{(1 / 2 \sqrt{2}) n-\sigma_{m, 2}^{\prime}}
$$

where

$$
n=\sqrt{\left(\sigma_{1}-\sigma_{2}\right)^{2}+\left(\sigma_{2}-\sigma_{3}\right)^{2}+\left(\sigma_{1}-\sigma_{3}\right)^{2}} .
$$

Substituting equations (24) and (25) into equation (29), we can get

$$
n=2 \sigma_{1}^{2}-4 \frac{P}{1-\eta^{2}} \sigma_{1}+\frac{2 P^{2}}{\left(1-\eta^{2}\right)}\left(1+\frac{r_{0}^{4}}{r^{4}}\right) \text {. }
$$

Next, we calculate the peak strength of the thick-walled cylinders according to the test results. The inner wall radius $r_{0}$ of this batch of specimens are $5 \mathrm{~mm}, 7.5 \mathrm{~mm}$, and $10 \mathrm{~mm}$. For the sampling points with different radius $r$, where $\left(r-r_{0}\right) /\left(R-r_{0}\right)=$ $1,1 / 2,1 / 3,1 / 4,1 / 5,1 / 6,1 / 7,1 / 8,1 / 9$, and $1 / 10$, we calculate their $m$ under different confining pressures, including $5 \mathrm{MPa}$, $10 \mathrm{MPa}, 15 \mathrm{MPa}, 20 \mathrm{MPa}, 30 \mathrm{MPa}$, and $40 \mathrm{MPa}$ (see Tables 3-5). 
TABLE 3: The value of $m$ in the specimen with an aperture of $10 \mathrm{~mm}$.

\begin{tabular}{|c|c|c|c|c|c|c|c|c|c|c|c|}
\hline \multicolumn{2}{|c|}{$\left(r-r_{0}\right) /\left(R-r_{0}\right)$} & 1 & $1 / 2$ & $1 / 3$ & $1 / 4$ & $1 / 5$ & $1 / 6$ & $1 / 7$ & $1 / 8$ & $1 / 9$ & $1 / 10$ \\
\hline$\sigma_{3}$ & $\sigma_{1}$ & \multicolumn{10}{|c|}{$m$} \\
\hline 5 & 177.3 & 8.3978 & 8.3975 & 8.3972 & 8.3966 & 8.3957 & 8.3943 & 8.3917 & 8.3860 & 8.3701 & 8.2889 \\
\hline 10 & 220.5 & 8.4858 & 8.4853 & 8.4846 & 8.4837 & 8.4821 & 8.4796 & 8.4750 & 8.4651 & 8.4372 & 8.3219 \\
\hline 15 & 261.1 & 8.5357 & 8.5350 & 8.5340 & 8.5326 & 8.5304 & 8.5269 & 8.5203 & 8.5064 & 8.4674 & 8.3284 \\
\hline 20 & 296.2 & 8.6032 & 8.6024 & 8.6013 & 8.5996 & 8.5970 & 8.5927 & 8.5849 & 8.5682 & 8.5217 & 8.3468 \\
\hline 30 & 337.3 & 8.6781 & 8.6769 & 8.6753 & 8.6730 & 8.6694 & 8.6634 & 8.6525 & 8.6292 & 8.5650 & 8.3685 \\
\hline 40 & 372.5 & 8.7475 & 8.7460 & 8.7440 & 8.7410 & 8.7364 & 8.7288 & 8.7148 & 8.6852 & 8.6041 & 8.3956 \\
\hline \multicolumn{2}{|c|}{ Average of $m$} & 8.5746 & 8.5738 & 8.5727 & 8.5710 & 8.5685 & 8.5642 & 8.5565 & 8.5400 & 8.4942 & 8.3416 \\
\hline \multicolumn{2}{|c|}{ Variance of $m$} & 0.9627 & 0.9625 & 0.9623 & 0.9619 & 0.9613 & 0.9603 & 0.9582 & 0.9530 & 0.9330 & 0.3459 \\
\hline
\end{tabular}

TABLE 4: The value of $m$ in the specimen with an aperture of $15 \mathrm{~mm}$.

\begin{tabular}{|c|c|c|c|c|c|c|c|c|c|c|c|}
\hline \multicolumn{2}{|c|}{$\left(r-r_{0}\right) /\left(R-r_{0}\right)$} & 1 & $1 / 2$ & $1 / 3$ & $1 / 4$ & $1 / 5$ & $1 / 6$ & $1 / 7$ & $1 / 8$ & $1 / 9$ & $1 / 10$ \\
\hline$\sigma_{3}$ & $\sigma_{1}$ & \multicolumn{10}{|c|}{$m$} \\
\hline 5 & 200.8 & 8.4103 & 8.4100 & 8.4096 & 8.4091 & 8.4082 & 8.4067 & 8.4040 & 8.3981 & 8.3816 & 8.2976 \\
\hline 10 & 233.1 & 8.4572 & 8.4567 & 8.4559 & 8.4548 & 8.4531 & 8.4503 & 8.4451 & 8.4341 & 8.4031 & 8.3243 \\
\hline 15 & 254.7 & 8.5435 & 8.5428 & 8.5428 & 8.5403 & 8.5381 & 8.5343 & 8.5275 & 8.5129 & 8.4722 & 8.3422 \\
\hline 20 & 294.5 & 8.6039 & 8.6030 & 8.6018 & 8.6000 & 8.5972 & 8.5927 & 8.5843 & 8.5664 & 8.5169 & 8.3603 \\
\hline 30 & 237.7 & 8.6849 & 8.6837 & 8.6819 & 8.6794 & 8.6756 & 8.6692 & 8.6575 & 8.6327 & 8.5643 & 8.3825 \\
\hline 40 & 290.6 & 8.7239 & 8.7215 & 8.7182 & 8.7134 & 8.7060 & 8.6938 & 8.6715 & 8.6242 & 8.4966 & 8.3572 \\
\hline \multicolumn{2}{|c|}{ Average of $m$} & 8.5706 & 8.5696 & 8.5683 & 8.5661 & 8.5630 & 8.5578 & 8.5483 & 8.5281 & 8.4724 & 8.3440 \\
\hline \multicolumn{2}{|c|}{ Variance of $m$} & 0.9373 & 0.9358 & 0.9330 & 0.8632 & 0.9255 & 0.9163 & 0.8964 & 0.8376 & 0.9399 & 0.4931 \\
\hline
\end{tabular}

TABLe 5: The value of $m$ in the specimen with an aperture of $20 \mathrm{~mm}$.

\begin{tabular}{|c|c|c|c|c|c|c|c|c|c|c|c|}
\hline \multicolumn{2}{|c|}{$\left(r-r_{0}\right) /\left(R-r_{0}\right)$} & 1 & $1 / 2$ & $1 / 3$ & $1 / 4$ & $1 / 5$ & $1 / 6$ & $1 / 7$ & $1 / 8$ & $1 / 9$ & $1 / 10$ \\
\hline$\sigma_{3}$ & $\sigma_{1}$ & \multicolumn{10}{|c|}{$m$} \\
\hline 5 & 195.6 & 8.4269 & 8.4266 & 8.4262 & 8.4255 & 8.4245 & 8.4228 & 8.4197 & 8.4131 & 8.3944 & 8.3002 \\
\hline 10 & 220.4 & 8.4901 & 8.4895 & 8.4887 & 8.4875 & 8.4856 & 8.4825 & 8.4767 & 8.4645 & 8.4303 & 8.3551 \\
\hline 15 & 248.3 & 8.5666 & 8.5658 & 8.5647 & 8.5630 & 8.5605 & 8.5562 & 5485 & 8.5320 & 8.4860 & 8.3710 \\
\hline 20 & 280.5 & 8.6206 & 8.6196 & 8.6181 & 8.6160 & 8.6128 & 8.6075 & 8.5977 & 8.5769 & 8.5194 & 8.3859 \\
\hline 30 & 336.2 & 8.6733 & 8.6715 & 8.6689 & 8.6652 & 8.6594 & 8.6499 & 8.6326 & 8.5959 & 8.4959 & 8.4135 \\
\hline 40 & 300.7 & 8.8135 & 8.8107 & 8.8070 & 8.8015 & 8.7931 & 8.7791 & 8.7537 & 8.7000 & 8.5550 & 8.4421 \\
\hline \multicolumn{2}{|c|}{ Average of $m$} & 8.5985 & 8.5972 & 8.5956 & 8.5931 & 8.5893 & 8.5830 & 8.5715 & 8.5471 & 8.4802 & 8.3779 \\
\hline \multicolumn{2}{|c|}{ Variance of $m$} & 0.9728 & 0.9723 & 0.9716 & 0.9706 & 0.9688 & 0.9657 & 0.9588 & 0.9371 & 0.7405 & 0.4746 \\
\hline
\end{tabular}

The data above are processed to obtain more intuitive mathematical rules (see Figure 12). The value of $m$ ranges from 8.0 to 8.8 , and increases with the confining pressure [46, 66-68]. For different points in the sample, the average value of $m$ in each specimen remains steady at around 8.5. When the confining pressure keeps, the value of $m$ decreases from the outer wall to the inner wall. The value of $m$ is related to the degree of particle occlusion. It is high for the complete rock and decreases as the damage increases [72-76]. When the confining pressure grows, the value of $m$ increases. It indicates that the TCS of the sample increases with the confining pressure, which is consistent with the physical tests.
Through the curve fitting of $m$ and the confining pressure, we get the following results. $R^{2}$ increases continuously from the inner wall to the outer wall, and it reaches the maximum at the outermost part. Under the same confining pressure, the value of $m$ shows a decreasing trend from the outer wall to the inner wall of the specimen, indicating that the bearing capacity is getting lower inside. The inner wall is most likely to be damaged, which agrees well with the theoretical analysis results.

In general, the three-dimensional Hoek-Brown criterion applies to the study of deformation and strength characteristics of thick-walled cylinder granite specimens. 

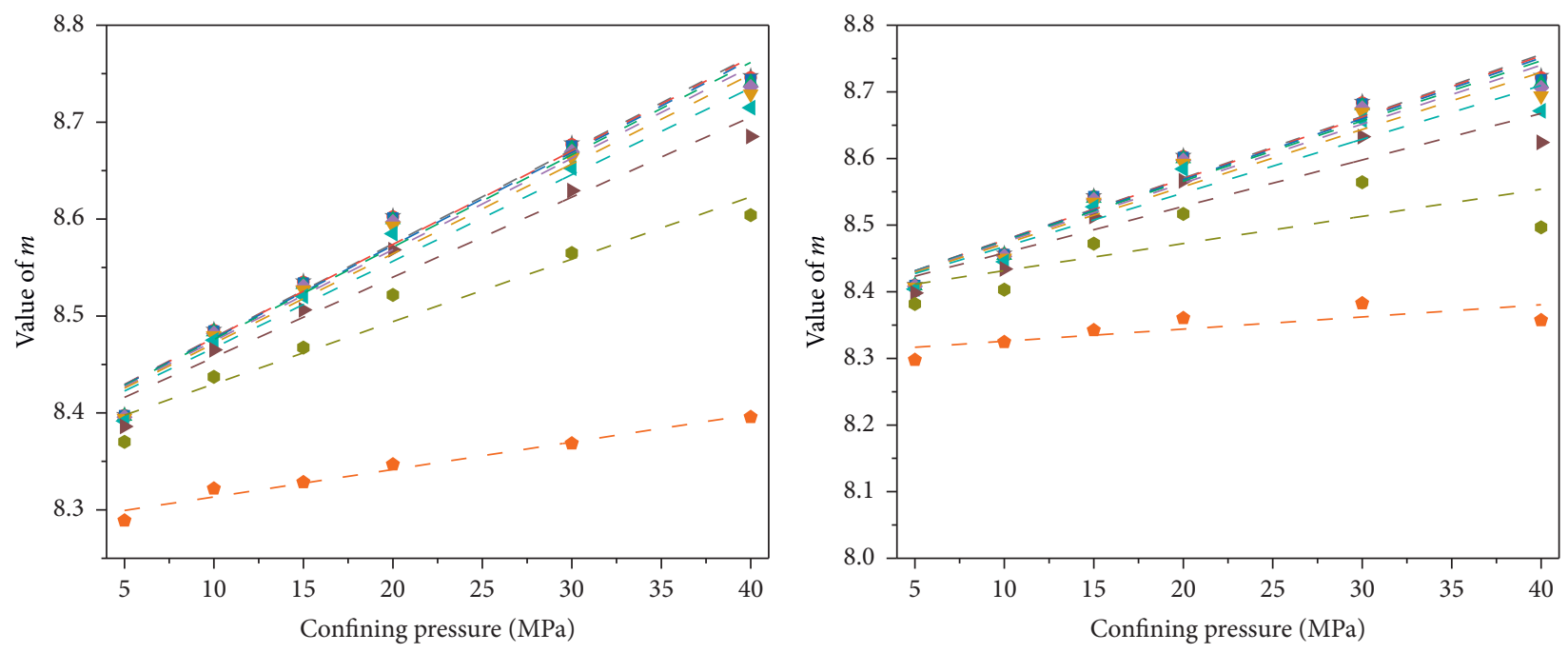

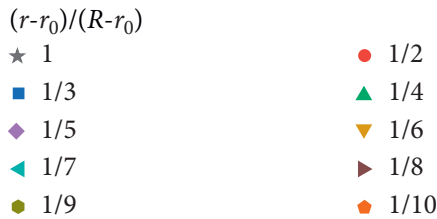

(a) $\left(r-r_{0}\right) /\left(R-r_{0}\right)$

$\begin{array}{ll}\star 1 & \bullet 1 / 2 \\ -1 / 3 & \Delta 1 / 4 \\ \bullet 1 / 5 & \nabla 1 / 6 \\ \triangleleft 1 / 7 & >1 / 8 \\ -1 / 9 & -1 / 10\end{array}$

(b)
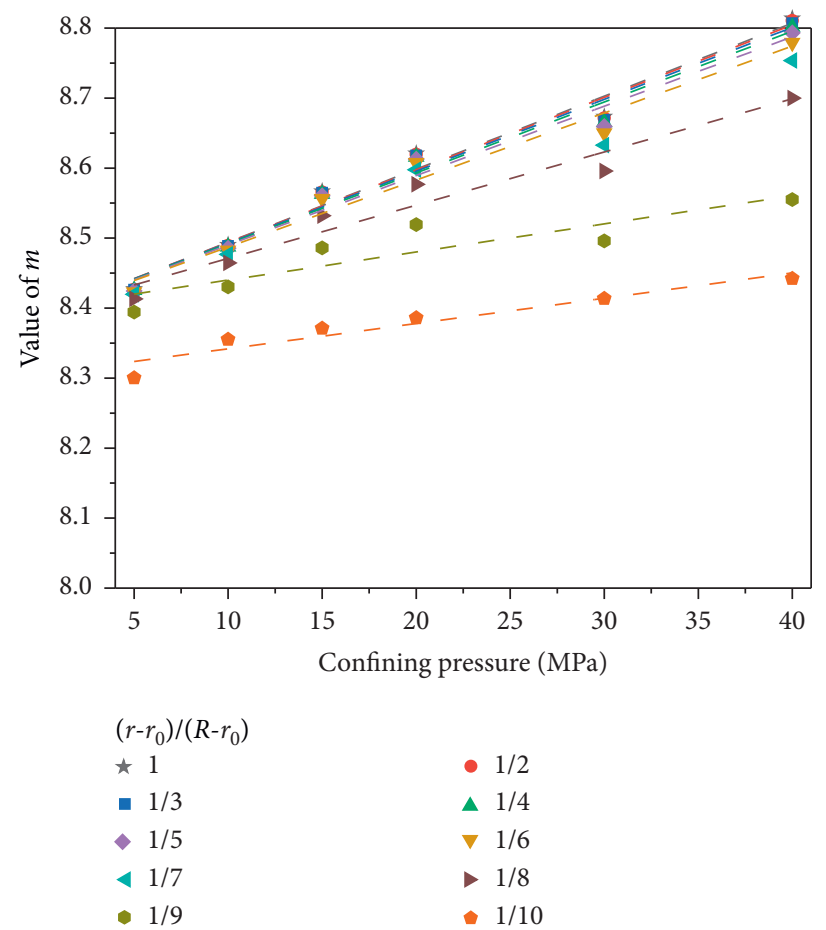

(c)

FIgURE 12: Scatter diagram of $m$ changing with confining pressure. (a) The specimens with an aperture of $10 \mathrm{~mm}$. (b) The specimens with an aperture of $15 \mathrm{~mm}$. (c) The specimens with an aperture of $20 \mathrm{~mm}$. 


\section{Conclusions}

In light of the above work, the main conclusions of this paper are as follows:

(1) No matter how confining pressure and pore size change, there exists no obvious yield stage in axial stress-strain curves.

(2) Coulomb criterion can only be applied to determine the cohesion and internal friction angle of the complete specimen but not to the thick-walled cylinders.

(3) Generally, the peak triaxial compression strength (TCS) of the specimen shows an increasing trend with confining pressure. When the confining pressure is small, the TCS differences between the complete and thick-walled cylinders are less. The elastic modulus increases with the confining pressure, while pore diameter has no obvious influence on it.

(4) The main failure modes under triaxial compression are shear failure and splitting failure. When the confining pressure is low, it presents shear failure. When the confining pressure reaches $30 \mathrm{MPa} 40 \mathrm{MPa}$, the splitting fracture appears. The area of fracture surface increases with the confining pressure.

(5) Measured from the outer to the inner wall of the thick-walled cylinders, the average value of the parameter $m$ keeps round 8.5. Besides, the value of $m$ shows a decreasing trend from the outer wall to the inner wall. It means that the outer wall of the specimen has the greatest bearing capacity, and the inner wall is most likely to be damaged. The results agree well with the theoretical analysis of the tests.

\section{Data Availability}

The numerical data used to support the findings of this study are included within the article.

\section{Conflicts of Interest}

The authors declare that there are no known conflicts of interest associated with this publication and there has been no significant financial support for this work that could have influenced its outcome.

\section{Acknowledgments}

The authors thank Xinyu Ding and Zhenxing Lu for useful discussions and early contributions to the project and Min Wang for very helpful comments on the manuscript. This research was funded by the National Natural Science Foundation of China (Grants nos. 51774132, 51774131 and 51974118), the Natural Science Foundation of Hunan Province (Grants nos. 2020JJ5188), and the Research Project of Department of Natural Resources of Hunan Province (Grants nos. 2020-10).

\section{References}

[1] G. Wang, Y. Luo, X. Li, T. Liu, R. Ma, and D. Qu, "Study on dynamic mechanical properties and meso-damage mechanism of jointed rock under impact load," European Journal of Environmental and Civil Engineering, vol. 23, pp. 1-17, 2019.

[2] R. Cao, P. Cao, X. Fan, X. Xiong, and H. Lin, "An experimental and numerical study on mechanical behavior of ubiquitous-joint brittle rock-like specimens under uniaxial compression," Rock Mechanics and Rock Engineering, vol. 49, no. 11, pp. 4319-4338, 2016.

[3] Y. Zhao, L. Zhang, J. Liao et al., "Experimental study of fracture toughness and subcritical crack growth of three rocks under different environments," International Journal of Geomechanics, vol. 20, no. 8, Article ID 04020128, 2020.

[4] M. Wang, W. Wan, and Y. Zhao, "Experimental study on crack propagation and the coalescence of rock-like materials with two preexisting fissures under biaxial compression," Bulletin of Engineering Geology and the Environment, vol. 79, no. 6, pp. 3121-3144, 2020.

[5] Y. Zhao, L. Zhang, W. Wang, J. Tang, H. Lin, and W. Wan, "Transient pulse test and morphological analysis of single rock fractures," International Journal of Rock Mechanics and Mining Sciences, vol. 91, pp. 139-154, 2017.

[6] Q. Wu, L. Chen, B. Shen, B. Dlamini, S. Li, and Y. Zhu, "Experimental investigation on rockbolt performance under the tension load," Rock Mechanics and Rock Engineering, vol. 52, no. 11, pp. 4605-4618, 2019.

[7] L. Dong, D. Sun, W. Shu, and X. Li, "Exploration: safe and clean mining on earth and asteroids," Journal of Cleaner Production, vol. 257, Article ID 120899, 2020.

[8] H. Lin, W. Xiong, Z. Xiong, and F. Gong, "Three-dimensional effects in a flattened Brazilian disk test," International Journal of Rock Mechanics and Mining Sciences, vol. 74, pp. 10-14, 2015.

[9] L. Dong, W. Zou, X. Li, W. Shu, and Z. Wang, "Collaborative localization method using analytical and iterative solutions for microseismic/acoustic emission sources in the rockmass structure for underground mining," Engineering Fracture Mechanics, vol. 210, pp. 95-112, 2019.

[10] S. Yang, Y. Huang, and P. G. Ranjith, "Failure mechanical and acoustic behavior of brine saturated-sandstone containing two pre-existing flaws under different confining pressures," Engineering Fracture Mechanics, vol. 193, pp. 108-121, 2018.

[11] X. Zhou, G. Li, and H. Ma, "Real-time experiment investigations on the coupled thermomechanical and cracking behaviors in granite containing three pre-existing fissures," Engineering Fracture Mechanics, vol. 224, Article ID 106797, 2020.

[12] R. Cao, P. Cao, H. Lin, G. Ma, X. Fan, and X. Xiong, "Mechanical behavior of an opening in a jointed rock-like specimen under uniaxial loading: experimental studies and particle mechanics approach," Archives of Civil and Mechanical Engineering, vol. 18, no. 1, pp. 198-214, 2018.

[13] Y. Zhao, L. Zhang, W. Wang et al., "Experimental study on shear behavior and a revised shear strength model for infilled rock joints," International Journal of Geomechanics, vol. 20, no. 9, Article ID 04020141, 2020.

[14] X. Zhou, Y. Zhang, Q. Ha, and K. Zhu, "Micromechanical modelling of the complete stress-strain relationship for crack weakened rock subjected to compressive loading," Rock 
Mechanics and Rock Engineering, vol. 41, no. 5, pp. 747-769, 2008.

[15] H. Lin, H. Yang, Y. Wang, Y. Zhao, and R. Cao, "Determination of the stress field and crack initiation angle of an open flaw tip under uniaxial compression," Theoretical and Applied Fracture Mechanics, vol. 104, Article ID 102358, 2019.

[16] H. Lin, W. Xiong, and Q. Yan, "Modified formula for the tensile strength as obtained by the flattened Brazilian disk test," Rock Mechanics and Rock Engineering, vol. 49, no. 4, pp. 1579-1586, 2016.

[17] X. Zhou, "Localization of deformation and stress-strain relation for mesoscopic heterogeneous brittle rock materials under unloading," Theoretical and Applied Fracture Mechanics, vol. 44, no. 1, pp. 27-43, 2005.

[18] X. Zhou and H. Yang, "Dynamic damage localization in crack-weakened rock mass: strain energy density factor approach," Theoretical and Applied Fracture Mechanics, vol. 97, pp. 289-302, 2018.

[19] C. D. Martin and N. A. Chandler, "The progressive fracture of Lac du Bonnet granite," International Journal of Rock Mechanics and Mining Sciences \& Geomechanics Abstracts, vol. 31, no. 6, pp. 643-659, 1994.

[20] L. Xue, S. Qin, Q. Sun, Y. Wang, L. M. Lee, and W. Li, “A study on crack damage stress thresholds of different rock types based on uniaxial compression tests," Rock Mechanics and Rock Engineering, vol. 47, no. 4, pp. 1183-1195, 2014.

[21] E. Ghazvinian, M. S. Diederichs, D. Labrie, and C. D. Martin, "An investigation on the fabric type dependency of the crack damage thresholds in brittle rocks," Geotechnical and Geological Engineering, vol. 33, no. 6, pp. 1409-1429, 2015.

[22] M. Cai, P. K. Kaiser, Y. Tasaka, T. Maejima, H. Morioka, and M. Minami, "Generalized crack initiation and crack damage stress thresholds of brittle rock masses near underground excavations," International Journal of Rock Mechanics and Mining Sciences, vol. 41, no. 5, pp. 833-847, 2004.

[23] J. S. Kim, K. S. Lee, W. J. Cho, H. J. Choi, and G. C. Cho, "A comparative evaluation of stress-strain and acoustic emission methods for quantitative damage assessments of brittle rock," Rock Mechanics and Rock Engineering, vol. 48, no. 2, pp. 495-508, 2014.

[24] B. Damjanac and C. Fairhurst, "Evidence for a long-term strength threshold in crystalline rock," Rock Mechanics and Rock Engineering, vol. 43, no. 5, pp. 513-531, 2010.

[25] C. Zhang, Y. Wang, and T. Jiang, "The propagation mechanism of an oblique straight crack in a rock sample and the effect of osmotic pressure under in-plane biaxial compression," Arabian Journal of Geosciences, vol. 13, no. 15, p. 736, 2020.

[26] E. R. Hoskins, "The failure of thick-walled hollow cylinders of isotropic rock," International Journal of Rock Mechanics and Mining Sciences \& Geomechanics Abstracts, vol. 6, no. 1, pp. 99-125, 1969.

[27] M. I. Alsayed, "Utilising the Hoek triaxial cell for multiaxial testing of hollow rock cylinders," International Journal of Rock Mechanics and Mining Sciences, vol. 39, no. 3, pp. 355-366, 2002.

[28] N. C. Gay, "Fracture growth around openings in thick-walled cylinders of rock subjected to hydrostatic compression," International Journal of Rock Mechanics and Mining Sciences \& Geomechanics Abstracts, vol. 10, no. 3, pp. 209-233, 1973.

[29] A. P. Fantilli and P. Vallini, "Crushing failure in hollow cylinders made of quasi-brittle materials," Computers \& Structures, vol. 88, no. 7-8, pp. 426-436, 2010.
[30] X. Zhou and H. Yang, "Micromechanical modeling of dynamic compressive responses of mesoscopic heterogenous brittle rock," Theoretical and Applied Fracture Mechanics, vol. 48, no. 1, pp. 1-20, 2007.

[31] D. H. Lee, C. Juang, J. Chen, H. Lin, and W. H. Shieh, "Stress paths and mechanical behavior of a sandstone in hollow cylinder tests," International Journal of Rock Mechanics and Mining Sciences, vol. 36, no. 7, pp. 857-870, 1999.

[32] S. Yang, "Experimental study on deformation, peak strength and crack damage behavior of hollow sandstone under conventional triaxial compression," Engineering Geology, vol. 213, pp. 11-24, 2016.

[33] J. Handin, H. C. Heard, and J. N. Magouirk, "Effects of the intermediate principal stress on the failure of limestone, dolomite, and glass at different temperatures and strain rates," Journal of Geophysical Research, vol. 72, no. 2, pp. 611-640, 1967.

[34] H. Zhang, Y. He, H. Liu, L. Han, and P. Shao, "Ringlike failure experiment of thick-walled limestone cylinder specimens in triaxial unloading tests," Mining Science and Technology (China), vol. 21, no. 3, pp. 445-450, 2011.

[35] L. Han, Y. He, and H. Zhang, "Study of rock splitting failure based on griffith strength theory," International Journal of Rock Mechanics and Mining Sciences, vol. 83, pp. 116-121, 2016.

[36] L. G. Margolin, "A generalized Griffith criterion for crack propagation," Engineering Fracture Mechanics, vol. 19, no. 3, pp. 539-543, 1984.

[37] Y. Zhao, "Griffith's criterion for mixed mode crack propagation," Engineering Fracture Mechanics, vol. 26, no. 5, pp. 683-689, 1987.

[38] Q. Wu, X. Li, M. Tao, F. Zhao, L. Weng, and L. Dong, "Conventional triaxial compression on hollow cylinders of sandstone with various fillings: relationship of surrounding rock with support," Journal of Central South University, vol. 25, no. 8, pp. 1976-1986, 2018.

[39] Q. Wu, L. Weng, Y. Zhao et al., "Deformation and cracking characteristics of ring-shaped granite with inclusion under diametrical compression," Arabian Journal of Geosciences, vol. 13, no. 14, p. 681, 2020.

[40] S. Wang, X. Li, K. Du, S. Wang, and M. Tao, "Experimental study of the triaxial strength properties of hollow cylindrical granite specimens under coupled external and internal confining stresses," Rock Mechanics and Rock Engineering, vol. 51, no. 7, pp. 2015-2031, 2018.

[41] J. Labuz and A. Zang, "Mohr-coulomb failure criterion," The ISRM Suggested Methods for Rock Characterization, Testing and Monitoring: 2007-2014, pp. 227-231, Springer, Berlin, Germany, 2015.

[42] W. Zhou and C. Hoek-Brown, Encyclopedia of Engineering Geology, P. T. Bobrowsky and B. Marker, Eds, Springer, Berlin, Germany, 2016.

[43] H. Yang, "Investigation into effect of excavation method on surrounding rock stability under bias tunnel," in Mechanics and Mechatronics, pp. 409-418, World Scientific, Singapore, 2015.

[44] H. Gong, L. Jin, H. Tao et al., "Effects of the unloading rate on the deformation and damage of the surrounding rock under different confining pressure," Chinese Journal of Rock Mechanics and Engineering, vol. 38, no. 3, pp. 433-444, 2019.

[45] Y. Wang, H. Zhang, H. Lin, Y. Zhao, and Y. Liu, "Fracture behaviour of central-flawed rock plate under uniaxial compression," Theoretical and Applied Fracture Mechanics, vol. 106, Article ID 102503, 2020. 
[46] Q. Wu, L. Weng, Y. Zhao, B. Guo, and T. Luo, "On the tensile mechanical characteristics of fine-grained granite after heating/cooling treatments with different cooling rates," Engineering Geology, vol. 253, pp. 94-110, 2019.

[47] W. Chen, W. Wan, Y. Zhao, and W. Peng, "Experimental study of the crack predominance of rock-like material containing parallel double fissures under uniaxial compression," Sustainability, vol. 12, no. 12, Article ID 5188, 2020.

[48] X. Zhou, "Dynamic damage constitutive relation of mesoscopic heterogenous brittle rock under rotation of principal stress axes," Theoretical and Applied Fracture Mechanics, vol. 54, no. 2, pp. 110-116, 2010.

[49] L. Zhang and H. Zhu, "Three-dimensional Hoek-Brown strength criterion for rocks," Journal of Geotechnical and Geoenvironmental Engineering, vol. 133, no. 9, pp. 1128-1135, 2007.

[50] Y. Zhao, Y. Wang, W. Wang, L. Tang, Q. Liu, and G. Cheng, "Modeling of rheological fracture behavior of rock cracks subjected to hydraulic pressure and far field stresses," Theoretical and Applied Fracture Mechanics, vol. 101, pp. 59-66, 2019.

[51] Q. Wu, X. Li, L. Weng, Q. Li, Y. Zhu, and R. Luo, "Experimental investigation of the dynamic response of prestressed rockbolt by using an SHPB-based rockbolt test system," Tunnelling and Underground Space Technology, vol. 93, p. 103088, 2019.

[52] M. Wang and W. Wan, "A new empirical formula for evaluating uniaxial compressive strength using the Schmidt hammer test," International Journal of Rock Mechanics and Mining Sciences, vol. 123, Article ID 104094, 2019.

[53] M. H. Leite, D. E. Gill, and R. Corthésy, "Experimental and numerical evaluation of stress redistribution in thick-walled rocksalt cylinders," International Journal of Rock Mechanics and Mining Sciences, vol. 35, no. 3, pp. 367-383, 1998.

[54] C. Zhang, P. Zou, Y. Wang et al., "An elasto-visco-plastic model based on stress functions for deformation and damage of water-saturated rocks during the freeze-thaw process," Construction and Building Materials, vol. 250, Article ID 118862, 2020.

[55] X. Zhou, "Upper and lower bounds for constitutive relation of crack-weakened rock masses under dynamic compressive loads," Theoretical and Applied Fracture Mechanics, vol. 46, no. 1, pp. 75-86, 2006.

[56] S. Xie and W. Wan, "Mechanical damage to the diorite caused by acid corrosion," Geotechnical and Geological Engineering, vol. 38, no. 3, pp. 3087-3094, 2020.

[57] Y. Lin, K. Deng, Y. Sun et al., "Burst strength of tubing and casing based on twin shear unified strength theory," PLOS One, vol. 9, no. 11, Article ID 0111426, 2014.

[58] S. Jin, Z. Wang, and Z. Liu, "Study on twin shear strength theory," Applied Mechanics and Materials, vol. 166-169, Article ID 3004, 2012.

[59] J. Y. Lee, H. R. Ryu, and Y. T. Park, "Finite element implementation for computer-aided education of structural mechanics: mohr's circle and its practical use," Computer Applications in Engineering Education, vol. 22, no. 3, pp. 494-508, 2014.

[60] D. H. Lee, C. Juang, H. Lin, and S. H. Yeh, "Mechanical behavior of tien-liao mudstone in hollow cylinder tests," Canadian Geotechnical Journal, vol. 39, no. 3, pp. 744-756, 2002.

[61] Y. Guo, C. Yang, and H. Mao, "Mechanical properties of jintan mine rock salt under complex stress paths,"
International Journal of Rock Mechanics and Mining Sciences, vol. 56, pp. 54-61, 2012.

[62] E. Eberhardt, "The hoek-Brown failure criterion," Rock Mechanics and Rock Engineering, vol. 45, no. 6, pp. 981-988, 2012.

[63] E. Hoek and E. T. Brown, "The Hoek-Brown failure criterion and GSI-2018 edition," Journal of Rock Mechanics and Geotechnical Engineering, vol. 11, no. 3, pp. 445-463, 2019.

[64] C. Zhong and Z. Yang, "Estimation method of rockmass strength parameters based on Hoek-Brown criterion," Applied Mechanics and Materials, vol. 501-504, pp. 380-383, 2014.

[65] A. E. Aladejare and Y. Wang, "Probabilistic characterization of hoek-Brown constant mi of rock using hoek's guideline chart, regression model and uniaxial compression test," Geotechnical and Geological Engineering, vol. 37, no. 6, pp. 5045-5060, 2019.

[66] J. Liu and G. Jiang, "Use of laboratory indentation tests to study the surface crack propagation caused by various indenters," Engineering Fracture Mechanics, Article ID 107421, 2020.

[67] Y. Zhao, C. Zhang, Y. Wang, and H. Lin, "Shear-related roughness classification and strength model of natural rock joint based on fuzzy comprehensive evaluation," International Journal of Rock Mechanics and Mining Sciences, Article ID 104550, 2020.

[68] Y. Zhao, C. Wang, and J. Bi, "Analysis of Fractured Rock Permeability Evolution Under Unloading Conditions by the Model of Elastoplastic Contact Between Rough Surfaces," Rock Mechanics and Rock Engineering, vol. 53, no. 12, pp. 5795-5808, 2020.

[69] S. A. L. Read and L. Richards, "A comparative study of mi, the Hoek-Brown constant for intact rock material," in Proceedings of 12th ISRM Congress, Beijing, China, October 2011.

[70] X. Pan and J. A. Hudson, "A simplified three dimensional Hoek-Brown yield criterion," in Proceedings of ISRM International Symposium, Madrid, Spain, September 1988.

[71] M. Cai, "Influence of intermediate principal stress on rock fracturing and strength near excavation boundaries-Insight from numerical modeling," International Journal of Rock Mechanics and Mining Sciences, vol. 45, no. 5, pp. 763-772, 2008.

[72] W. R. Judd, "Underground excavations in rock," Engineering Geology, vol. 19, no. 3, pp. 244-246, 1983.

[73] C. Zhang, H. Lin, C. Qiu, T. Jiang, and J. Zhang, "The effect of cross-section shape on deformation, damage and failure of rock-like materials under uniaxial compression from both a macro and micro viewpoint," International Journal of Damage Mechanics, vol. 29, no. 7, pp. 1076-1099, 2020.

[74] J. Liu, W. Wan, Y. Zhao, and X. Fan, "Stress evolution in punch-through shear tests: a numerical study based on discrete element method," Frontiers in Physics, vol. 8, no. 327, 2020.

[75] Y. Zhao, Y. Wang, W. Wang, W. Wan, and J. Tang, "Modeling of non-linear rheological behavior of hard rock using triaxial rheological experiment," International Journal of Rock Mechanics and Mining Sciences, vol. 93, pp. 66-75, 2017.

[76] X. Zhou, Q. Ha, Y. Zhang, and K. Zhu, “Analysis of deformation localization and the complete stress-strain relation for brittle rock subjected to dynamic compressive loads," International Journal of Rock Mechanics and Mining Sciences, vol. 41, no. 2, pp. 311-319, 2004. 